\title{
Optimization of WEDM process parameters by RSM in machining of stir cum squeeze cast $A 413-B_{4} C$ composites
}

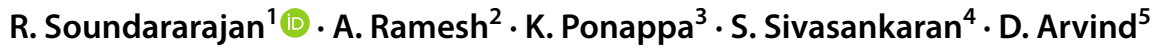

Received: 27 March 2020 / Accepted: 23 August 2020 / Published online: 6 October 2020

(c) Springer Nature Switzerland AG 2020

\begin{abstract}
In this paper, aluminium alloy metal matrix composites were manufactured via stir cum squeeze casting technique owing to their tremendous automotive and aviation applications. The aluminium alloy with 12 weight percentage boron carbide (A413 with $12 \mathrm{wt} \% \mathrm{~B}_{4} \mathrm{C}$ ) composites was prepared with optimal stir cum squeeze casting parameters like applied squeeze pressure of $140 \mathrm{MPa}, 225^{\circ} \mathrm{C}$ preheated die temperature and $12 \mathrm{wt} \%$ of $\mathrm{B}_{4} \mathrm{C}$ particles which yielded pore-free fine-grained equally distributed ceramic particles of the composite, leading to an enhanced higher hardness of $136 \mathrm{VHN}$ and higher tensile value of $373 \mathrm{MPa}$ due to squeezing pressure and $\mathrm{B}_{4} \mathrm{C}$ particles. The prime intern of the wire electrical discharge machining process was adopted for investigating the machinability of stir cum squeeze cast high-strength A413 with $12 \mathrm{wt} \% \mathrm{~B}_{4} \mathrm{C}$ composite. The stratagem of response surface methodology along through central composite rotatable design was taken towards systematic design of experiments. The experimental study results exhibited a possibility of higher amount of metal removal rate for maximum pulse on-time and peak current values, and also better surface roughness was acquired for higher values of pulse off time. The mathematical model shows excellent prediction in accordance with experimental data which seems to fall inside the bounds of acceptable average error around $6.47 \%$ and $1.52 \%$ for metal removal rate and surface roughness through additivity tests, respectively. The proposed multiresponse optimization results revealed a great potential for improving machined surface quality which could be utilized according to the industrial requirements.
\end{abstract}

Keywords Stir cum squeeze cast composites · WEDM $\cdot$ Process parameter $\cdot$ Optimization $\cdot$ RSM

\begin{tabular}{llll}
\multicolumn{2}{l}{ List of symbols } & EDM & Spark electric discharge machining \\
$\mathrm{MMCs}$ & Metal matrix composites & WEDM & Wire electric discharge machining \\
$\mathrm{B} \mathrm{C}_{4} \mathrm{C}$ & Boron carbide & $\mathrm{A} / \mathrm{Al}$ & Aluminium \\
$\mathrm{SiC}$ & Silicon carbide & $\mathrm{AA}$ & Aluminium alloy \\
$\mathrm{TiC}$ & Titanium carbide & wt\% & Weight percentage \\
$\mathrm{Al}_{4} \mathrm{C}_{3}$ & Aluminium carbide & Ton & Pulse on-time \\
$\mathrm{Al}_{2} \mathrm{O}_{3}$ & Aluminium oxide & Toff & Pulse off-time \\
$\mathrm{SiO}_{2}$ & Silicon dioxide & IP & Peak current \\
$\mathrm{TiB}_{2}$ & Titanium diboride & MRR & Metal removal rate \\
$\mathrm{C}_{2} \mathrm{Cl}_{6}$ & Hexachloroethane & SR & Surface roughness \\
$\mathrm{K}_{2} \mathrm{TiF}_{6}$ & Potassium hexafluorotitanate & ASTM & American Society for Testing and Materials \\
${ }^{\circ} \mathrm{C}$ & Degree celsius & SEM & Scanning electron microscopy
\end{tabular}

R. Soundararajan, soundararajan.mtech@gmail.com | ${ }^{1}$ Department of Mechanical Engineering, Sri Krishna College of Engineering and Technology, Coimbatore, India. ${ }^{2}$ Department of Mechanical Engineering, Chennai Institute of Technology, Chennai, India. ${ }^{3}$ Design and Manufacturing, PDPM Indian Institute of Information Technology, Jabalpur, India. ${ }^{4}$ Department of Mechanical Engineering, College of Engineering, Qassim University, Buraydah, Kingdom of Saudi Arabia. ${ }^{5}$ The TIPS Global Institute, Coimbatore, India. 


$\begin{array}{ll}\text { DOE } & \text { Design of experiments } \\ \text { RSM } & \text { Response surface methodology } \\ \text { CCRD } & \text { Central composite rotatable design } \\ \text { ANOVA } & \text { Analysis of variance } \\ \mathrm{VHN} & \text { Vickers hardness number } \\ \mathrm{MPa} & \text { Megapascal } \\ \mathrm{mho} & \text { Reciprocal of ohm } \\ \mathrm{V} & \text { Voltage } \\ \mathrm{Kg} / \mathrm{cm}^{2} & \text { Kilogram per square centimetre } \\ \mathrm{DC} & \text { Direct current } \\ \mathrm{mm} / \mathrm{min} & \text { Millimetre cube per minute } \\ \mu \mathrm{m} & \text { Micro-meter }\end{array}$

\section{Introduction}

The physical, mechanical and tribological behaviour of ceramic particle-reinforced MMCs is better than their parent metals. MMCs show the combinational benefits of both the matrix and reinforcements [1]. Among the accessible MMCs, the ideal alternative is aluminium-based MMCs on account of their intrinsic properties like lightweight, higher strength and stiffness, better thermal conductivity, low thermal expansion, poor electrical conductivity, and low wear resistance [2]. Non-oxide ceramics alike borides, nitrides, carbides and silicides are significant engineering materials in contrast with oxides offering improved refractoriness, higher strength and stiffness and enhanced thermal shock resistance at higher temperatures. These hard ceramic materials in particulate form are synthesized with aluminium parental matrix to form the metal matrix composites. These hard particles are in standard dissemination towards matrix which improves massive characteristics of the metal matrix composites [3]. Common ceramic particulates used to reinforce aluminium matrix alloys are $\mathrm{B}_{4} \mathrm{C}, \mathrm{SiC}$, $\mathrm{TiC}, \mathrm{Al}_{4} \mathrm{C}_{3}, \mathrm{Al}_{2} \mathrm{O}_{3}, \mathrm{SiO}_{2}$, and $\mathrm{TiB}_{2}$. Among these reinforced particulates, $\mathrm{B}_{4} \mathrm{C}$ ceramic particulate reinforcements possess low density, high temperature withstand ability, high strength and more wear resistance; hence, it is often chosen. Literature reports have revealed that various fabricating procedures are viable when reinforced by $\mathrm{B}_{4} \mathrm{C}$ particles in aluminium matrix, and the boron carbide particulate reinforcement in aluminium alloys is suitable for high-temperature applications due to its rudimentary properties [4]. Wettability of ceramic particles in the molten aluminium metal can be upgraded by the adoption of $\mathrm{K}_{2} \mathrm{TiF}_{6}$ halide salt for the duration of casting for enhanced bonding among aluminium alloy and $\mathrm{B}_{4} \mathrm{C}$ particles and thus obtaining improved metallurgical and mechanical behaviour of the prepared composites [5].

The MMCs are prepared using different fabrication techniques. Among them, liquid-state method is more viable and economical one. The primary factor which affects the behaviour of the composites in the liquid-state processing route (stir casting) is stirring speed, and, on the other hand, the stirring time also deliberates some effect on percentage of reinforcement addition in the matrix [6]. Among available modern liquid casting techniques, the squeeze casting gives quality surface finish with very little operating costs and excludes the micro-porosity defects making it the most effective manufacturing process to manufacture components with high precision and with enhanced properties than gravity die casting or pressure die casting [7]. The bonding, diffusion, and scattering of reinforcement elements inside the matrix play significant role in metal matrix composites casting while attaining preferred properties. High pressure is applied during the squeeze casting process leading to enhancement of bonding of reinforcement particles in molten metal and obtaining pore-free dense casting within a very short span of time [8]. In squeeze casting, the applied squeeze pressure and a nominal weight percentage of particles within the matrix provide porosity-free uniform distribution with closely bonded particles and fine grain dendritic structures, leading to enhanced strength of the composites [9].

Machining is the most important phase in manufacturing. The parts are manufactured by casting; forming and other shaping processes often require post- or secondary-processing operations before the product is ready for real-time applications. MMCs are difficult for conventional machining due to their extreme abrasive properties [10]. A few literature reports revealed that the conventional machining is impractical for machining MMCs due to their considerable requirement of power, poor machinability and surface profile, high tooling costs, serious wear of the cutting tool, and producing complex shapes becomes more tedious [11]. The major non-conventional machining methods of spark EDM followed by WEDM and magnetic field-assisted WEDM are relatively thriving for removing materials of superalloys or composites with higher surface integrity [12]. WEDM suits best for machining aluminium matrix composites since it is being used to machine the intricate and complex components for aerospace and automotive industries. Many researchers investigated on WEDM for various alloys, and MMCs are being produced through stirred gravity casting technique [13]. During machining of the stir casted specimens like AISi7mg with $20 \mathrm{wt} \% \mathrm{SiC}$ and $\mathrm{A} 413$ with $9 \mathrm{wt} \% \mathrm{~B}_{4} \mathrm{C}$ having a higher percentage of reinforcement composites, craters occur on the machined surface due to influenced WEDM process parameters of high discharge energy, voltage and pulse on time passing through it. Further, the recast layers are composed of a higher percentage of ceramic particles protruding on the surfaces leading to an uneven machining surface $[14,15]$. WEDM is suitable for cutting AA6351 
with 5 wt $\% \mathrm{SiC}$ and $5 \mathrm{wt} \% \mathrm{~B}_{4} \mathrm{C}$ hybrid metal matrix composites which shows having more pores on the machined region.[16]. Al 7075 alloy reinforced with $1.5 \mathrm{wt} \% \mathrm{~B}_{4} \mathrm{C}$ and $1.5 \mathrm{wt} \%$ fly ash nanoparticles hybrid composites was being considered for machining through EDM process. The surface characteristics observations revealed that high input energy melts more sufficient material with greater crater generating coarser surface texture [17]. A new combination of fabricated hybrid metal matrix composite of $A 359$ with $2.5 \mathrm{wt} \% \mathrm{~B}_{4} \mathrm{C}$ and $2.5 \mathrm{wt} \% \mathrm{Al}_{2} \mathrm{O}_{3}$ is being made up in-house by electromagnetic stir casting. The machined surface had many peaks and valleys with moderate of flaws such as surface porosity [18]. Machinability study of composites is prepared using WEDM route, and after machining of AA2024 with 2.5 wt $\% \mathrm{ZrB}_{2}$ composite, it showed better surface roughness value than higher weight percentage addition of reinforcement particles in the matrix [19]. The machined surface integrity/quality directly depends on reinforcement addition, composites preparation method, and WEDM influenced process parameters like Ton, Toff, IP, etc. Similarly, the presence of higher weight percentage addition of particles in matrix results in higher hardness and strength. The machinability of these composites directly influences the WEDM process parameters $[20,21]$. Experimentation has been done on stir cast $\mathrm{A} 413$ with $9 \mathrm{wt} \%$ of $\mathrm{B}_{4} \mathrm{C}$ reinforcement which is then processed by micro-EDM to investigate the output for various input process variables such as the rate of feed on MRR, voltage, capacitance, SR, and kerf width. Several researchers acknowledged that the wire drum speed, the pulse current; the pulse on and off time are the influencing process variables in WEDM. The experimental results of the MMCs showed that the wire drum speed has a minor impact on the SR and MRR in comparison with other factors like peak current, pulse off time, and pulse on time correspondingly [22].

Experiments have been performed utilizing the design of experiments technique since it is more precise, more effective, and less expensive. Some of the design techniques are factorial designs, Taguchi methods, genetic algorithm, RSM, etc., [23]. A stir cast AA5083 with 7 wt\% $\mathrm{B}_{4} \mathrm{C}$ composites was taken for WEDM process parameters optimization by using metaheuristic techniques [24]. Grey-based Taguchi technique has been chosen as an optimum parameter combination to achieve the performance features of maximum MRR, minimum roughness value, $\mathrm{B}_{4} \mathrm{C} 6 \mathrm{wt} \%$, aluminium alloy 6063 [25]. Since the time consumption for arrival of results is more in the existing experimental approach, RSM is used as an effective tool for improving, optimizing, and evolving the processes by coalescing numerous input factors and assessing how their intricate interactions influence the performance of the response factors $[26,27]$. RSM exhibits a statistical method for the design of experiments. The other techniques like CCRD are adopted for analyzing the performance of the projected model and improving the model which is subsequently identified by response graphs. Further, the impact of input factors on responses can be analysed by ANOVA test. Mathematical models for the optimization of WEDM characteristics are developed by RSM technique [28, 29]. CCRD is one of the widely used experimental design methods of RSM. The key benefits of CCRD are as follows: It provides design points beyond the predetermined range of factors as axial points $(a)$. This in turn offers good predicting ability of the developed model over the design space along with better accuracy than that of other approach $[30,31]$. The RSM technique seems to be more promising in predicting the response via mathematical modelling over the other techniques [30-32].

All the available literature reports of various MMCs were mainly focusing on stirring with the gravity casting process, followed by WEDM process. There are sufficient research reports available on the fabrication of pore-free fine-grain high-strength aluminium metal matrix composites done through stir cum squeeze casting technique and performed for metallurgical and mechanical characterization study. As mentioned, very few studies have undertaken composites, that too only stirred with gravity casting processes on WEDM. But there is no report on optimizing the WEDM process parameters on aluminium metal matrix composites done through stir cum squeeze casting technique. The variation of casting/composites process parameter is not the main intent of our work. The exploration of the machinability of stir cum squeeze cast $A 413-B_{4} C$ composites through WEDM is the key objective of the research which is deemed vital. The manufacturers of WEDM would give the optimal range of parameters for very few material combinations which is commercially available. However, an extensive study on optimal WEDM process parameters for high-strength newly developed stir cum squeeze cast A413- $\mathrm{B}_{4} \mathrm{C}$ composites is an essential thing for the manufacturing industries. The usage of appropriate machining parameters forms the base for optimum usage of WEDM process. This investigation is based on focusing to plot the effects of WEDM influenced by several process variables like pulse on time and off time, followed by peak current on the MRR and SR while machining stir cum squeeze cast $A 413-B_{4} C$ composites by using CCRD in RSM. From the systematic experiments, a mathematical model has been established to predict the responses contained in the affordable error region, in agreement with the experimental responses. Also a multi-constrained optimization model using the desirability approach for MRR and SR in WEDM parametric combination is formulated. The machined surface quality and integrity were observed through scanning electron microscopy which revealed good bonding, 
Table 1 Chemical composition of A413 aluminium alloy

\begin{tabular}{|c|c|c|c|c|c|c|c|c|c|c|c|}
\hline Elements & $\mathrm{Cu}$ & $\mathrm{Mg}$ & $\mathrm{Si}$ & $\mathrm{Fe}$ & $\mathrm{Mn}$ & $\mathrm{Ni}$ & $\mathrm{Zn}$ & $\mathrm{Pb}$ & Sn & $\mathrm{Ti}$ & $\mathrm{Al}$ \\
\hline Standard & $0.25 \max$ & $0.15 \max$ & $10.0-13.0$ & $0.60 \max$ & $0.50 \max$ & $0.10 \max$ & $0.30 \max$ & $0.10 \max$ & $0.10 \max$ & $0.20 \max$ & Remainder \\
\hline Tested & 0.1 & 0.1 & 11.81 & 0.56 & 0.5 & 0.1 & 0.1 & 0.1 & 0.05 & 0.1 & Remainder \\
\hline
\end{tabular}

Table 2 Chemical composition of pure boron carbide $\left(\mathrm{B}_{4} \mathrm{C}\right)$ with $98.1 \mathrm{wt} \%$ of purity

\begin{tabular}{llllllll}
\hline Elements & $\mathrm{B}$ & $\mathrm{C}$ & $\mathrm{Ca}$ & $\mathrm{Fe}$ & $\mathrm{Si}$ & $\mathrm{F}$ & $\mathrm{Cl}$ \\
\hline Standard \% & 80.0 & 18.1 & 0.3 & 1.0 & 0.5 & 0.025 & 0.075 \\
\hline
\end{tabular}

fine structure, elimination of particle pullout/plucking and absence of surface micro-cracks due to stir cum squeezing casting processing composites was being considered.

\section{Casting and machining experimental details}

\subsection{Material details}

A soft nature of aluminium alloy A413 was chosen as the matrix material because of $2.66 \mathrm{~g} / \mathrm{cm}^{3}$ of density being suitable for different industrial applications in the current scenario. The advantage of this alloy is its exceptional distinctive mechanical properties, better fluidity, castability and corrosion resistance coupled with better machinability. Table 1 illustrates the chemical composition of A413 aluminium alloy.

Boron carbide $\left(\mathrm{B}_{4} \mathrm{C}\right)$ well known as the third toughest material following to diamond and cubic boron nitride is preferred as a reinforcement particle having $2.52 \mathrm{~g} / \mathrm{cm}^{3}$ density, which is a very hard ceramic particle with low specific gravity, good chemical stability, high thermal, wear and impact resistance that offers advantages in applications involving neutron absorption capability. Table 2 gives the chemical composition pure boron carbide.

\subsection{Stir cum squeeze casting experimental set-up}

The stir casting machine consists of an electric furnace which could heat the material up to $1000^{\circ} \mathrm{C}$ with EN8 crucible being capable of melting an ingot weighing about $2 \mathrm{~kg}$. The machine has a leak-resistant bottom pouring unit and an insulated multi-layer for reducing the skin temperature, which is coupled to the electric furnace. The purpose of the special bottom pouring arrangement is to provide a pathway for the molten metal to be directly poured into the die from the furnace output via an electrically heated pathway. The die used to prepare the composite is permanent $\mathrm{H} 13$ steel die of dimensions $50 \mathrm{~mm}$ diameter and $200 \mathrm{~mm}$ height. An electrically operated rotary stirrer capable of a top rotational speed of $1500 \mathrm{rpm}$ is attached to the furnace for stirring the mixture to create a whirlpool in the liquid metal. The melt temperature is measured by the aid of a $K$-type thermocouple with a digital display that is also connected to the set-up. The die was preheated before the molten material was poured onto it. The temperatures at various points of the set-up such as the bottom pouring induction furnace, metal transfer pathway along stirrer speed can be monitored and controlled in the control panel. Figure 1 shows a 50 Ton motorized hydraulic set-up with a pressure indicator and a control panel. This set-up was used for applying the pressure over the molten metal inside the die which was hinged on the basement of hydraulic arrangement.

\subsection{Fabrication of composites and their properties}

The previous investigation by Soundararajan et al. [33] has reported about stir cum squeeze casting of A413 with $\mathrm{B}_{4} \mathrm{C}$ composites and the impacts of each squeeze casting parameters over the mechanical behaviour of hardness and tensile strength of the test sample. Based on the analysis, the conclusion explored that the optimal combination of the squeeze casting parameters considered was the squeeze pressure, weight $\%$ of $\mathrm{B}_{4} \mathrm{C}$ particles and die preheating temperature of $140 \mathrm{MPa}, 12 \mathrm{wt} \%$, and $225^{\circ} \mathrm{C}$, respectively. This combination of input parameters has yielded high-strength pore-free specimens.

Hence, A413 with 12 wt $\% B_{4} C$ composites in the present investigation was fabricated under this optimal stir cum squeeze casting process condition, and the samples were made and taken for WEDM process. The A413 alloy pure ingots of $1 \mathrm{Kg}$ were measured and melted $\left(725^{\circ} \mathrm{C}\right)$ in the steel crucible. The melt was cleaned by adding the $8 \mathrm{~g}$ weight of coat flux, and the entrapped gases were also removed by adding $\mathrm{C}_{2} \mathrm{Cl}_{6}$ degasser. $\mathrm{A}$ $12 \mathrm{wt} \%$ of boron carbide of size 44 microns along with $12 \mathrm{~g}$ of $\mathrm{K}_{2} \mathrm{TiF}_{6}$ were preheated $\left(500{ }^{\circ} \mathrm{C}\right)$ with the help of inbuilt preheated set-up. The purpose of adding $\mathrm{K}_{2} \mathrm{TiF}_{6}$ is to achieve proper wettability with the tight bound $\mathrm{B}_{4} \mathrm{C}$ particles to aluminium alloy melt. The preheated 
Fig. 1 Stir cum squeeze casting set-up

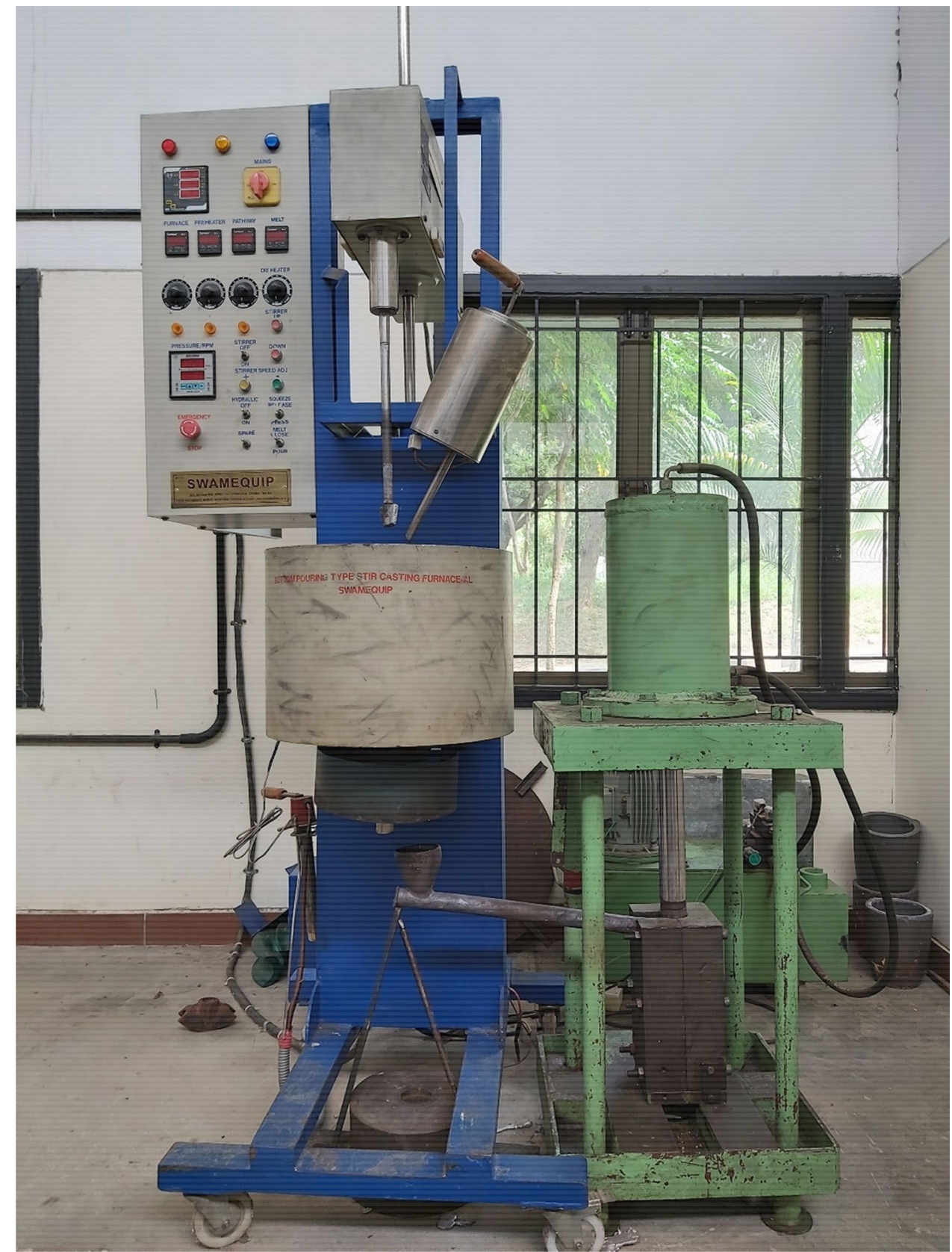

12 wt $\% \mathrm{~B}_{4} \mathrm{C}$ particle along with $\mathrm{K}_{2} \mathrm{TiF}_{6}$ was being slowly fed into the molten metal. For the avoidance of parting particles, agglomeration, thereby sustaining homogeneous distribution, the stirring was done for $5 \mathrm{~min}$ at $300 \mathrm{rpm}$. The colloidal graphite-coated $\mathrm{H} 13$ hot steel die was preheated to $225^{\circ} \mathrm{C}$, and the molten metal was transferred into it within few seconds to eliminate the heat loss and turbulence which occur due to the flow of the molten metal. A squeeze pressure of $140 \mathrm{MPa}$ was applied on the melt in the preheated mould with a delay time of about five seconds and retained over the solidifying mould for $60 \mathrm{~s}$ to produce the sound casting.
The cylindrical (50 mm diameter $x 150 \mathrm{~mm}$ height) cast sample is shown in Fig. 2.

Prior to machining of casted samples, few cast samples were subjected to metallurgical and mechanical testing conducted as per ASTM standards procedure for conforming the test results. By using scanning electron microscopy equipment, particle distribution was confirmed before machining. The SEM image of Fig. 3 revealed the equal dispersion with better bonding of $12 \mathrm{wt} \% \mathrm{~B}_{4} \mathrm{C}$ particles in A413 matrix, agglomeration-free composites were observed, and this evidence directly impacts on the mechanical properties. 
Fig. 2 A413 with $12 w t \% B_{4} C$ cast samples made from stir cum squeeze casting process


Fig. 3 a SEM image of stir cum squeeze casted $A 413$ with 12 wt $\% B_{4} C$ composites (100× magnification), b SEM image of stir cum squeeze casted A413 with 12 wt $\% B_{4}$ C composites (500× magnification)

Also by used Vickers hardness tester (DHR 1000), ZWICK universal testing system (2000 N capacity, microprocessor-controlled) hardness and strength were measured. The average tested results of the prepared composites obtained were higher hardness of $136 \mathrm{VHN}$, tensile and yield strength of $373 \mathrm{MPa}$ and $216 \mathrm{MPa}$, respectively, as shown in Fig. 4 with error bar.

Similar results were obtained by Soundararajan et al. [33] in which the mechanisms were described in detail already and also being found under optimal processing conditions of the composite samples that were being prepared prior to machining. A squeeze pressure of $140 \mathrm{MPa}$ resulted in the increase in heat transfer rate leading to progressive solidification, thereby eliminating the cluster formation, uniform distribution of the $\mathrm{B}_{4} \mathrm{C}$ particles in the composites and leading to a strong bond between the matrix and reinforcement, which results in improved load transference ability from the matrix to the reinforcement. Also applied squeeze pressure increases densification, thereby increasing grain boundary of particles within the matrix resulting in strengthening of the composites. It was noted that the addition of $\mathrm{B}_{4} \mathrm{C}$ particles of harder and stiffer material in the soft A413 alloy, leads to a obstacle for the dislocation motion, thereby increasing both yield strength and UTS as the $12 \mathrm{wt} \%$ of $\mathrm{B}_{4} \mathrm{C}$ increases the barrier to dislocation. The improvement in hardness of the composite was due to $\mathrm{B}_{4} \mathrm{C}$ particles with a hard surface that resists the localized plastic deformation. The negative effects of particle settling/cluster formation form agglomeration and porosity which acts as a stress concentration zone in the composite under loading. These factors are eliminated at $225^{\circ} \mathrm{C}$ of die preheating temperature, thereby producing the maximum results of the composites.

Followed by the remaining casted samples that exhibited higher strength and pore-free A413 with $12 \mathrm{wt} \% \mathrm{~B}_{4} \mathrm{C}$ composites were being taken for WEDM machining process in the present investigation. 
(a)

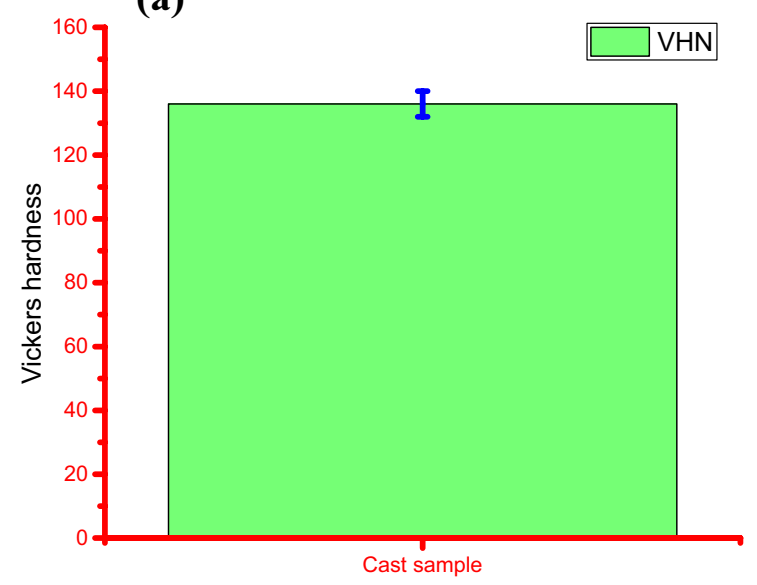

Stir cum squeeze casted A413 with 12 wt \% B4C composites

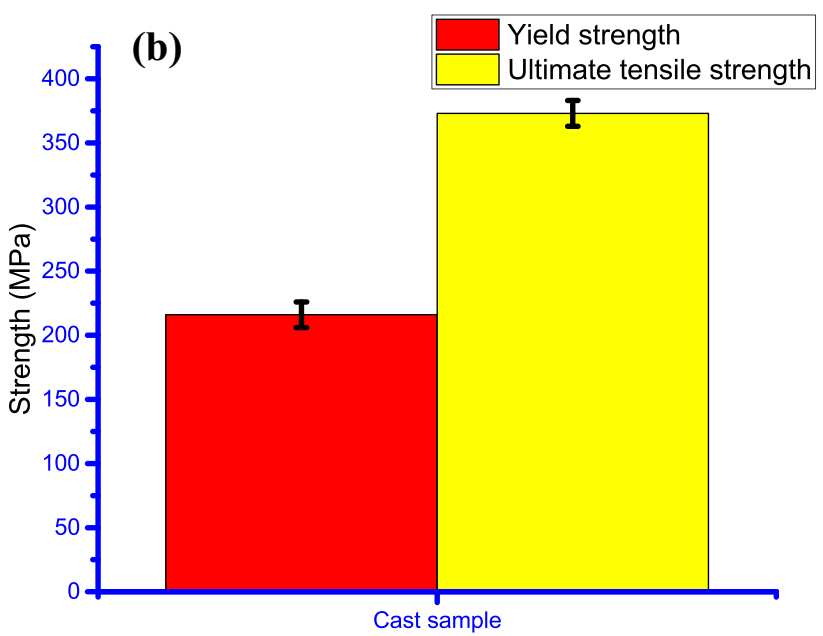

Stir cum squeeze casted A413 with 12 wt $\%$ B4C composites

Fig. 4 a Vickers hardness for stir cum squeeze casted $\mathrm{A} 413$ with 12 wt $\% \mathrm{~B}_{4} \mathrm{C}$ composites, $\mathbf{b}$ yield and ultimate tensile strength for stir cum squeeze casted $\mathrm{A} 413$ with $12 \mathrm{wt} \% \mathrm{~B}_{4} \mathrm{C}$ composites

\subsection{Design of experiments in WEDM process}

ELEKTRA SPRINTCUT 734 machine was used to conduct experiments. The brass wire coated with zinc of $0.25 \mathrm{~mm}$ diameter, dielectric medium of dielectric conductivity 20 mho de-mineralized water, 2 units wire feed, tension of wire 4 units, servo voltage as $20 \mathrm{~V}, 15 \mathrm{Kg} / \mathrm{cm}^{2}$ flushing pressure, 2100 unit servo feed and a peak voltage of 2 unit with $110 \mathrm{~V} D C$ were used during the experimental work. The prepared stir cum squeeze cast $A 413$ with 12 wt $\% B_{4} C$ composites cylindrical specimen of $15 \mathrm{~mm}$ thickness was obtained from a rectangular piece, and it was used as a work specimen as shown in Fig. 4 for ease of machining. Analysis of variance was done to see which variable creates the most impact on the eventual result. As a consequence of this, the pulse on time, pulse off time, peak current variable process parameters and the rest are constant constraints through pilot experimental trails for the initial cut and different outputs were observed. Based on the observation, Table 3 shows the working ranges of the influential parameters and its levels being selected for experimental design methodology with response surface methodology. Figure 5 shows the prepared specimen for machining final experimental runs as per the design matrix.

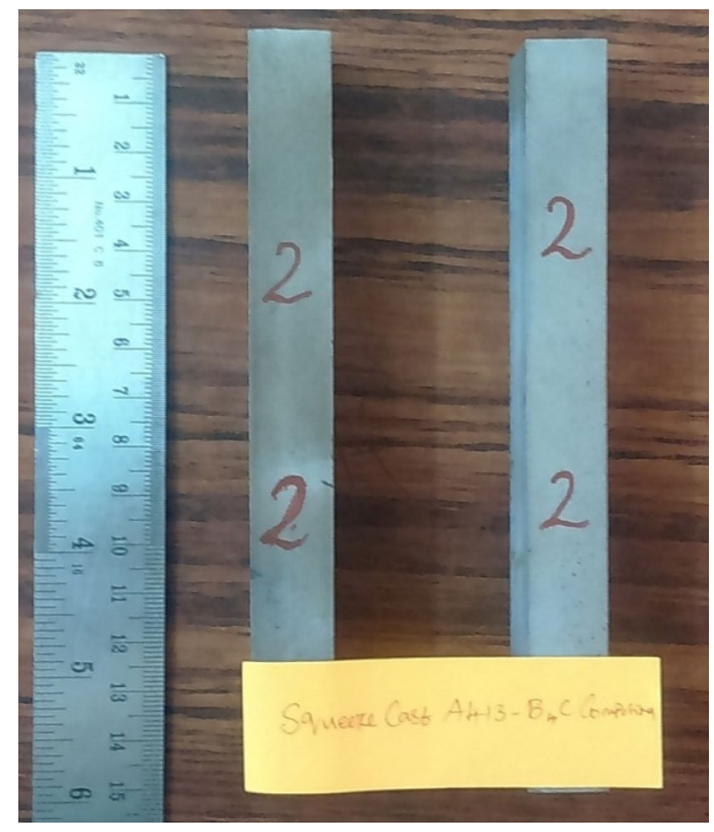

Fig. 5 Prepared stir cum squeeze casted $\mathrm{A} 413$ with 12 wt $\% B_{4} C$ composites sample for WEDM process
Table 3 Machining parameter used in the experiments

\begin{tabular}{lllccc}
\hline Parameter & Symbol & Unit & Low level $(-1)$ & Middle level $(0)$ & High level $(+1)$ \\
\hline Pulse on time & $T_{\text {on }}$ & $\mu \mathrm{s}$ & 109 & 115 & 121 \\
Pulse off time & $T_{\text {off }}$ & $\mu \mathrm{s}$ & 47 & 53 & 59 \\
Peak current & $\mathrm{IP}$ & Amps & 160 & 180 & 200 \\
\hline
\end{tabular}




\subsection{Response surface methodology}

The response surface methodology is a widely used technique in manufacturing applications to build up quantitative models. It is one of the most active and reliable statistical methods to create, analyse and manipulate the quadratic nature of the interdependency of the various variables under consideration. In the present study, RSM is used for modelling and analyzing the responses which are evaluated by performing experiment. Generally, the experimental data utmost fit into a quadratic model, and thus, Eq. (1) describes the second-order polynomial response.
CCRD technique, twenty different random experimental parametric combinations were taken.

\subsection{Measuring of experimental responses}

The MRR can be calculated by substituting the value of cutting speed, the kerf width and the kerf height in Eq. (2). The required cutting speed value is displayed on the computer display. At a distance of $4 \mathrm{~mm}$ from start, the removal of the cutting speed reading is noted to ensure the collection of stabilized values.

Mitutoyo's optical microscope is used to measure the

$Y=b_{0}+b_{2} x_{2}+b_{1} x_{1}+b_{3} x_{3}+b_{11} x_{1}^{2}+b_{23} x_{2}^{2}+b_{33} x_{3}^{2}+b_{12} x_{1} x_{2}+b_{13} x_{1} x_{3}+b_{23} x_{2} x_{3}$

where the response is denoted by ' $Y$ ' and the quantitative variables are denoted by $x_{1}, x_{2}$ and $x_{3}$. Likewise, the linear

Material removal rate $(\mathrm{MRR})=$ Cutting speed $*$ Kerf width $*$ Height $\left(\mathrm{mm}^{3} / \mathrm{min}\right)$ kerf width at $6 \mathrm{~mm}$ from the surface roughness cuttings. Three values of kerf width are obtained by measuring in different positions, and its mean was taken as kerf width to improve accuracy effects are denoted by $b_{1}, b_{2}$ and $b_{3}$ for $x_{1}, x_{2}$ and $x_{3}$; correspondingly, $b_{11}, b_{22}$ and $b_{33}$ are used to denote the quadratic effects of $\times 1, \times 2$ and $\times 3$ correspondingly. The $x_{1}$ and $x_{2}, x_{1}$ and $x_{3}, x_{2}$ and $x_{3}$ interactions in linear-linear fashion are denoted by $b_{12}, b_{13}$ and $b_{23}$, respectively. In the box and hunter technique in the centre, composite design was taken to access the coefficient of response. The response surface of the second order fits the model unerringly, and the replication was detached to find the error terms. The error of the mean square was determined by duplicating the points of the centre.

The design of 20 machining runs based on RSM is done in design expert software. A complete factorial CCRD was used to develop the design, and also, $T_{\text {on }}, T_{\text {off }}$ and IP were the input parameters that were conglomerated for determining their response. In this central composite rotatable design, the three-factor, three-level design is taken to initialize the most favourable response on MRR and SR of stir cum squeeze cast $A 413$ with 12 wt $\% B_{4} C$ composites processed by WEDM. The $T_{\text {on }}, T_{\text {off }}$ and IP were the variable parameters, and they were coded $-1,0$ and +1 . The output responses obtained are MRR and SR. The full factorial design technique of CCRD develops all the possible parametric possibilities of the various factors at two different levels (high +1 and low -1 ). The design is poised of the eight-star points, six central points (coded level 0 ) and six axial points $(+1.68179,-1.68179)$. In accordance with
Every three times for a cutting distance of $4 \mathrm{~mm}$, the $\mathrm{SR}$ values were measured in $\mu \mathrm{m}$ with the assistance of Mitutoyo's surface roughness testing device. The mean SR value is taken as the SR value for the analysis.

\section{Results and discussion}

\subsection{WEDM process with their interaction}

The various parametric levels of $T_{\text {on }}, T_{\text {off }}$ and IP in accordance with the DOE were used to machine the squeeze cast components. The MRR and SR values obtained were $3.251-25.575 \mathrm{~mm}^{3} / \mathrm{min}, 4.14-6.18 \mu \mathrm{m}$, respectively, for a low-high range of aforesaid parameters. Electrode wire cut-off was eliminated during the machining of composites because the $\mathrm{B}_{4} \mathrm{C}$ particulates were evenly distributed without any agglomeration and micro-porosity in the composites. As a result of being cast under optimal parametric conditions for the developed stir cum squeeze composites, the considerable amount of MRR and good SR were obtained because of pore-free high-strength $A 413$ reinforced with $12 \mathrm{wt} \%$ of $44 \mu \mathrm{m}$ size $\mathrm{B}_{4} \mathrm{C}$ particles. Experimental design with its outputs as illustrated in Table 4 and Fig. 6 indicates the machined specimens of stir cum squeeze cast $\mathrm{A} 413$ with 12 wt $\% \mathrm{~B}_{4} \mathrm{C}$ composites. 
Table 4 Design of experiments with obtained responses

\begin{tabular}{|c|c|c|c|c|c|c|c|c|c|}
\hline Std & Run & Block & $\mathrm{A}: T_{\text {on }} \mu \mathrm{s}$ & $\mathrm{B}: T_{\text {off }} \mu \mathrm{s}$ & C:Ip Amp & $\begin{array}{l}\text { Cutting velocity } \\
\mathrm{mm} / \mathrm{min} \mathrm{mm} / \mathrm{min}\end{array}$ & Kerf width mm & $\mathrm{R} 1: \mathrm{MRR} \mathrm{mm}^{3} / \mathrm{min}$ & $\mathrm{R} 2: \mathrm{SR} \mu \mathrm{m}$ \\
\hline 20 & 1 & Block 1 & 0.85 & 32.00 & 180.00 & 2.034 & 0.356 & 10.862 & 5.03 \\
\hline 12 & 2 & Block 1 & 0.85 & 52.00 & 180.00 & 1.404 & 0.359 & 7.561 & 4.72 \\
\hline 10 & 3 & Block 1 & 1.35 & 32.00 & 180.00 & 3.474 & 0.367 & 19.124 & 5.47 \\
\hline 9 & 4 & Block 1 & 0.35 & 32.00 & 180.00 & 0.63 & 0.344 & 3.251 & 4.4 \\
\hline 15 & 5 & Block 1 & 0.85 & 32.00 & 180.00 & 1.836 & 0.356 & 9.804 & 4.81 \\
\hline 11 & 6 & Block 1 & 0.85 & 12.00 & 180.00 & 3.996 & 0.352 & 21.099 & 5.18 \\
\hline 17 & 7 & Block 1 & 0.85 & 32.00 & 180.00 & 1.872 & 0.356 & 9.996 & 4.94 \\
\hline 8 & 8 & Block 1 & 1.15 & 44.00 & 200.00 & 2.538 & 0.369 & 14.048 & 5.11 \\
\hline 16 & 9 & Block 1 & 0.85 & 32.00 & 180.00 & 1.962 & 0.356 & 10.477 & 4.91 \\
\hline 13 & 10 & Block 1 & 0.85 & 32.00 & 150.00 & 1.01 & 0.323 & 4.935 & 4.14 \\
\hline 3 & 11 & Block 1 & 0.55 & 44.00 & 160.00 & 0.937 & 0.300 & 4.217 & 4.38 \\
\hline 4 & 12 & Block 1 & 1.15 & 44.00 & 160.00 & 1.26 & 0.354 & 6.691 & 4.59 \\
\hline 7 & 13 & Block 1 & 0.55 & 44.00 & 200.00 & 1.17 & 0.339 & 5.966 & 4.64 \\
\hline 2 & 14 & Block 1 & 1.15 & 20.00 & 160.00 & 2.862 & 0.337 & 14.467 & 5.04 \\
\hline 1 & 15 & Block 1 & 0.55 & 20.00 & 160.00 & 1.404 & 0.298 & 6.276 & 4.51 \\
\hline 19 & 16 & Block 1 & 0.85 & 32.00 & 180.00 & 1.926 & 0.356 & 10.285 & 4.87 \\
\hline 5 & 17 & Block 1 & 0.55 & 20.00 & 200.00 & 2.502 & 0.351 & 13.173 & 4.64 \\
\hline 14 & 18 & Block 1 & 0.85 & 32.00 & 210.00 & 3.432 & 0.384 & 19.769 & 5.12 \\
\hline 6 & 19 & Block 1 & 1.15 & 20.00 & 200.00 & 4.44 & 0.384 & 25.575 & 6.18 \\
\hline 18 & 20 & Block 1 & 0.85 & 32.00 & 180.00 & 1.728 & 0.356 & 9.228 & 4.98 \\
\hline
\end{tabular}

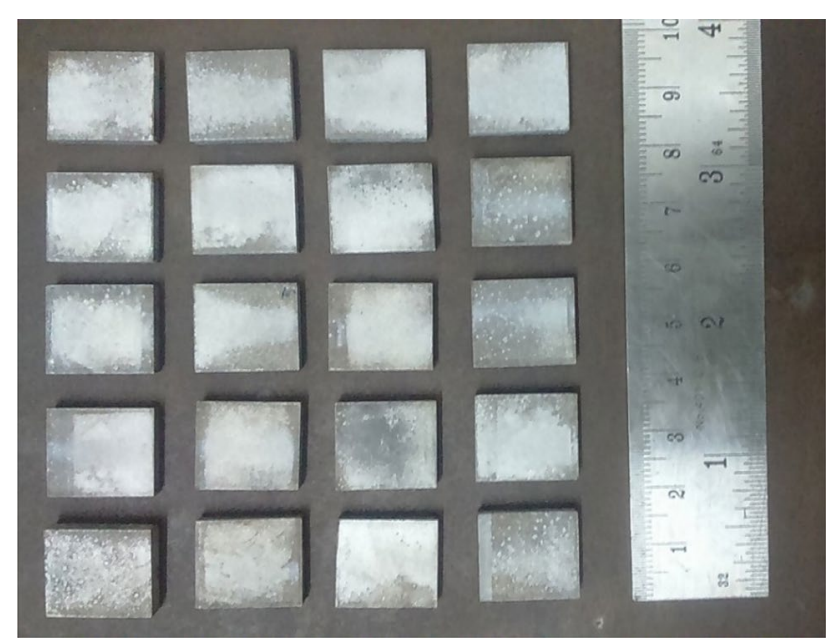

Fig. 6 Machined specimen of stir cum squeeze casted A413 with 12 wt $\% \mathrm{~B}_{4} \mathrm{C}$ composites

\subsection{WEDM process parameters effects on responses}

\subsubsection{Material removal rate analysis on machining composites}

Significant composites machining process parameters on WEDM such as maximum signal and minimal noise ratio were derived from ANOVA technique. ANOVA report shows that the $F$-value is 50.6 for MRR model, and this considered model is significant. It is clear that there is a chance of $0.01 \%$ error for "model $F$-value" to occur owing to an error level. Model terms tended to be significant by viewing " $P>F$ " (lower than 0.05500 ) values. The terms $A, B$, $C, A B, A C$ and $B C$ were the terms which were to represent interactions of every input WEDM process parameters. Moreover, $A, B$ and $C$ were acknowledged as the most significant factors. The values of $P>0.0500$ deliberate that these factors/terms of $A^{2}, B^{2}$ and $C^{2}$ in the model were non-significant. The noise causes an accidental chance of $1.78 \%$ in "lack-of-fit $F$-value". There was a sensible agreement of 0.8510 for "predicted R-squared" with "adjacent $\mathrm{R}$-squared" of 0.9592 . The ratio between signal and noise was seen through "adequate precision." It is desirable to obtain a ratio of larger than 4 ; this ratio of 27.062 hints the adequate signal. The normal plots of residual are presented in Fig. 7. A normally distributed residuals were seen through these plots; hence, it showcases that the developed model honestly fits the observed experimental values. Figure 8 shows the relation between the residual and predicted fits. These plots show that the residuals were structure less. Thus, Eq. 3 shows the second-order equation obtained for MRR. 


$$
\begin{aligned}
\text { MRR }= & 17.00812-12.87961 * T_{\text {on }}+0.29219 * T_{\text {off }} \\
& -0.26883 * \mathrm{lp}-0.34851 * T_{\text {on }} * T_{\text {off }}+0.20456 * T_{\text {on }} * \mathrm{Ip} \\
& -4.63490 E-003 * T_{\text {off }} * \mathrm{Ip}+0.78178 * T_{\text {on }}^{2} \\
& +8.20418 E-003 * T_{\text {off }}^{2}+1.20518 E-003 * \mathrm{Ip}^{2}
\end{aligned}
$$

In an analysis of variance, the input process parameters used for the experiment like $T_{\text {on }}, T_{\text {off }}$ and IP were initialized to be valid at $95 \%$ acceptance level. $T_{\text {on }}$ was the important factor that has the greatest impact on MRR with a contribution of $34.58 \%$, followed by IP and $\mathrm{T}_{\text {off }}$ which influences the output $28.01 \%$ and $27.24 \%$, respectively, as shown in Table 5. It was noted from Fig. 9 that the increase in MRR has occurred when $T_{\text {on }}$ and IP

Design-Expento Software
MRR
Color points by value of
MRR:
25.575
3.251

Fig. 7 Normal plot of residuals for MRR

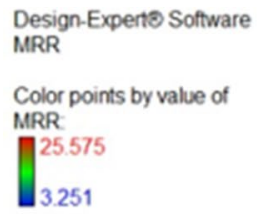

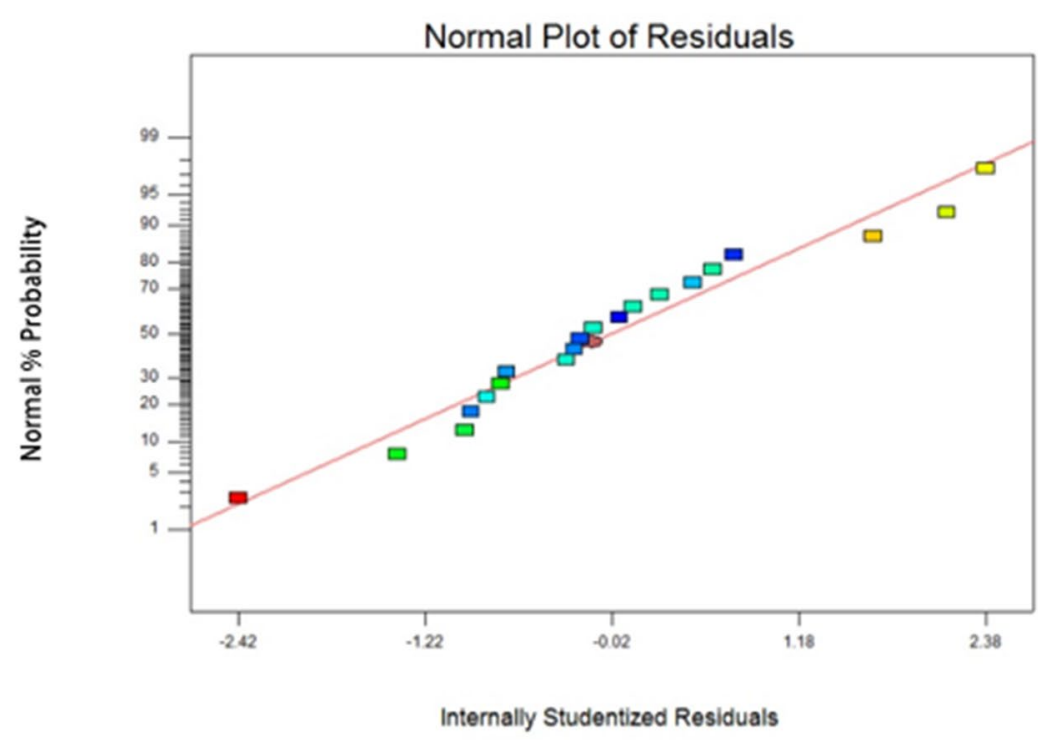

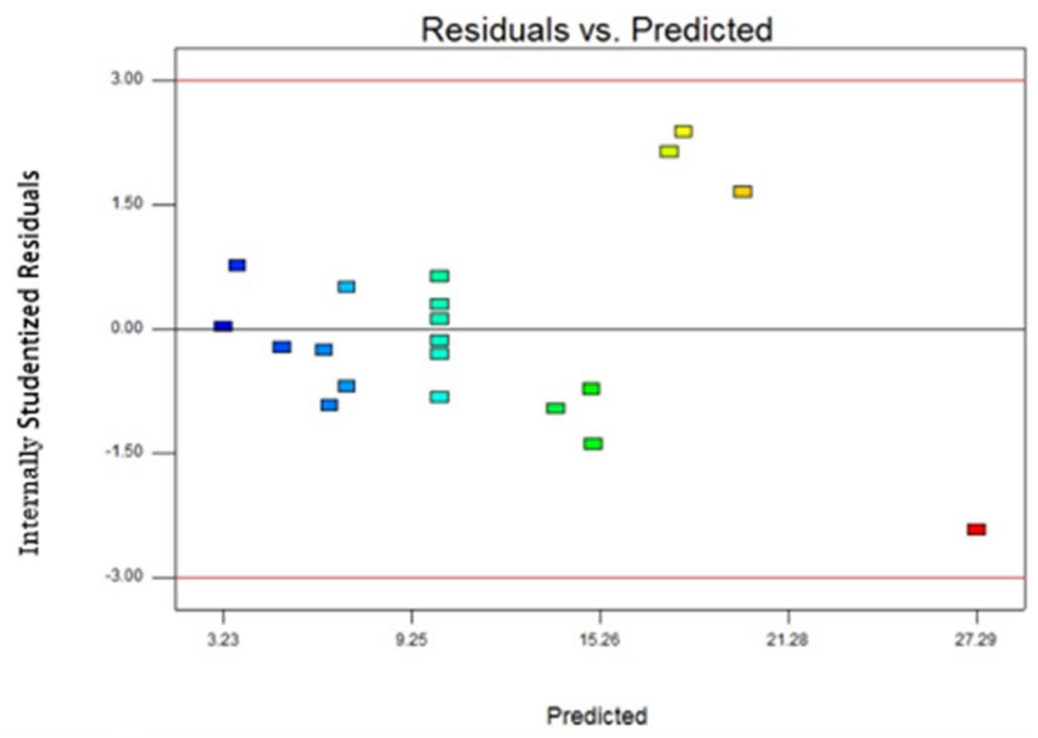

Fig. 8 Residual versus predicted plot for MRR 
Table 5 ANOVA for MRR

\begin{tabular}{|c|c|c|c|c|c|c|c|}
\hline Source & Sum of squares & DF & Mean of square & $F$ value & Contribution\% & $P$ value & Significant \\
\hline Model & 693.11 & 9 & 77.01 & 50.68 & 97.85 & $<0.0001$ & $*$ \\
\hline$A-T_{\text {on }}$ & 245.00 & 1 & 245.00 & 161.23 & 34.58 & $<0.0001$ & * \\
\hline$B-T_{\text {off }}$ & 192.98 & 1 & 192.98 & 127.00 & 27.24 & $<0.0001$ & * \\
\hline C-IP & 198.44 & 1 & 198.44 & 130.59 & 28.01 & $<0.0001$ & * \\
\hline$A B$ & 12.59 & 1 & 12.59 & 8.29 & 1.77 & 0.0164 & \\
\hline$A C$ & 12.05 & 1 & 12.05 & 7.93 & 1.70 & 0.0183 & \\
\hline BC & 9.90 & 1 & 09.90 & 6.51 & 1.39 & 0.0287 & \\
\hline$B \wedge 2$ & 20.11 & 1 & 3.35 & 2.20 & 2.83 & 0.1685 & \\
\hline Residual & 15.20 & 10 & 1.52 & & 2.14 & & \\
\hline Lack of fit & 13.58 & 5 & 2.72 & 8.41 & 1.91 & 0.0178 & \\
\hline Pure error & 1.62 & 5 & 0.32 & & 0.22 & & \\
\hline Total & 708.31 & 19 & & & 100.00 & & \\
\hline
\end{tabular}

R-Squared: 0.9785, adj R-squared: 0.9592, pred R-squared: 0.8510, adeq precision: 27.062

*Significant
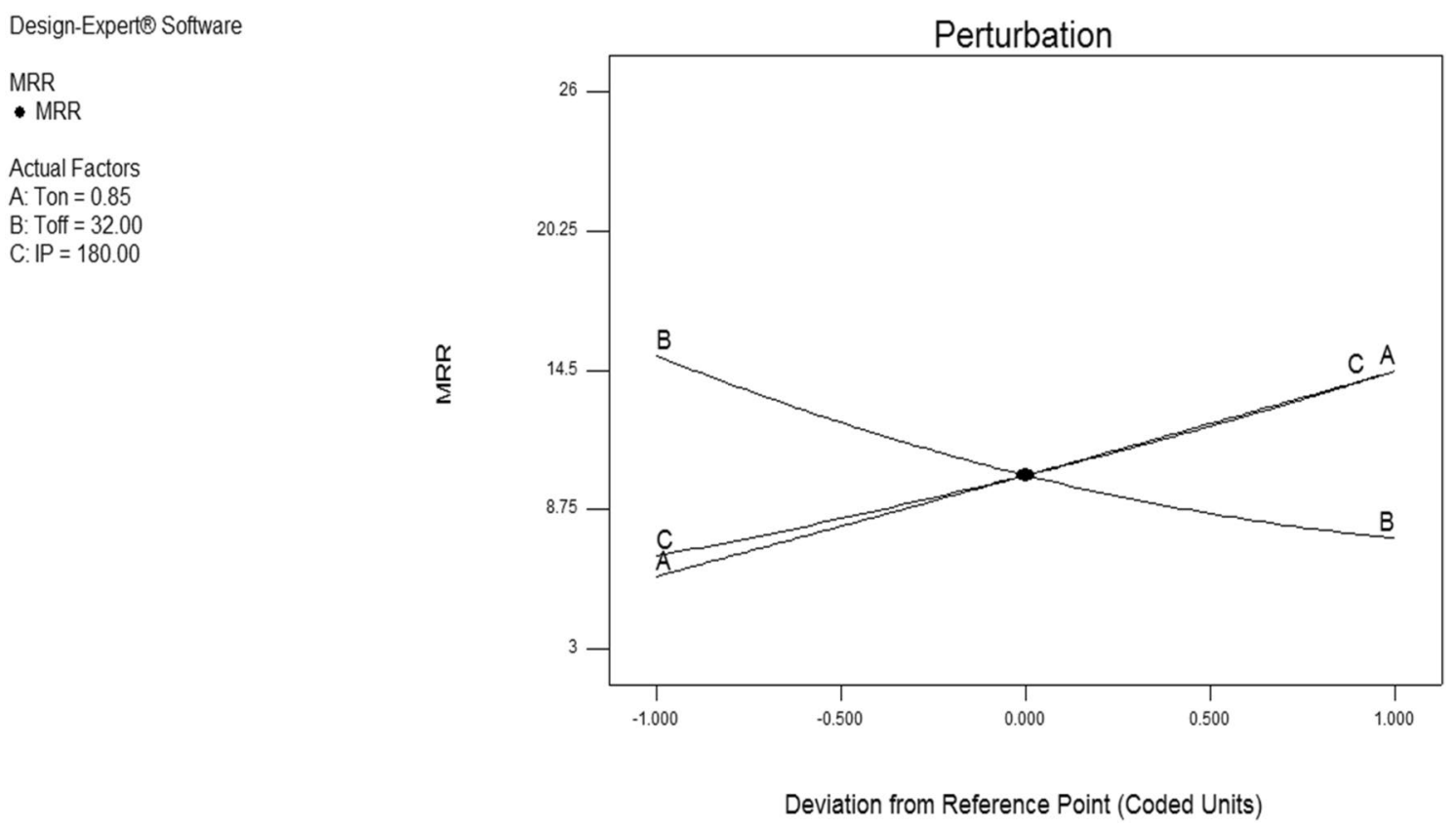

Fig. 9 Perturbation plot for MRR

started to increases. However, with an increase in $\mathrm{T}_{\text {off, }}$, the MRR starts to decreases gradually. From Fig. 10, it was witnessed that the MRR has started to increase gradually with the rise in $T_{\text {on }}$ and fall in $T_{\text {off }}$. Figure 11 shows that a gradual rise in $T_{\text {on }}$ and IP surges MRR. Figure 12 reveals that as the $T_{\text {off }}$ decreases and IP increases the MRR raises progressively.

It was experimentally observed that $T_{\text {on }}$ and IP were noticeable influencing parameters over MRR while machining stir cum squeeze cast $A 413$ with 12 wt\% $B_{4} C$ composite. With the increase in $T_{\text {on }}$, the sparking time increases which results in the transfer of high discharge energy at the cutting zone, thus leading to an increase in the MRR, which can also be increased by increasing the IP like an increase in the intensity of the spark at the cutting zone. By means of this cumulative effect, the amount of energy discharged per spark is more while producing the machining surface. In response, a huge amount of metal was melted in the spark gap. Thus, the stronger energy discharge was generated because of the better $T_{\text {on }}$ and IP value yields higher MRR. Though the MRR in WEDM operation was allied to the thermal diffusion of the material, it was calculated with means of thermal conductivity, bonding, reinforcement size, and density of the material. The 
Design-Expert@ Software

MRR

25.575
3.251

MRR $=9.804$

Std \# 19 Run \# 16

$\mathrm{X} 1=\mathrm{A}:$ Ton $=0.85$

$\mathrm{X} 2=\mathrm{B}:$ Toff $=32.00$

Actual Factor

C: $I P=180.00$

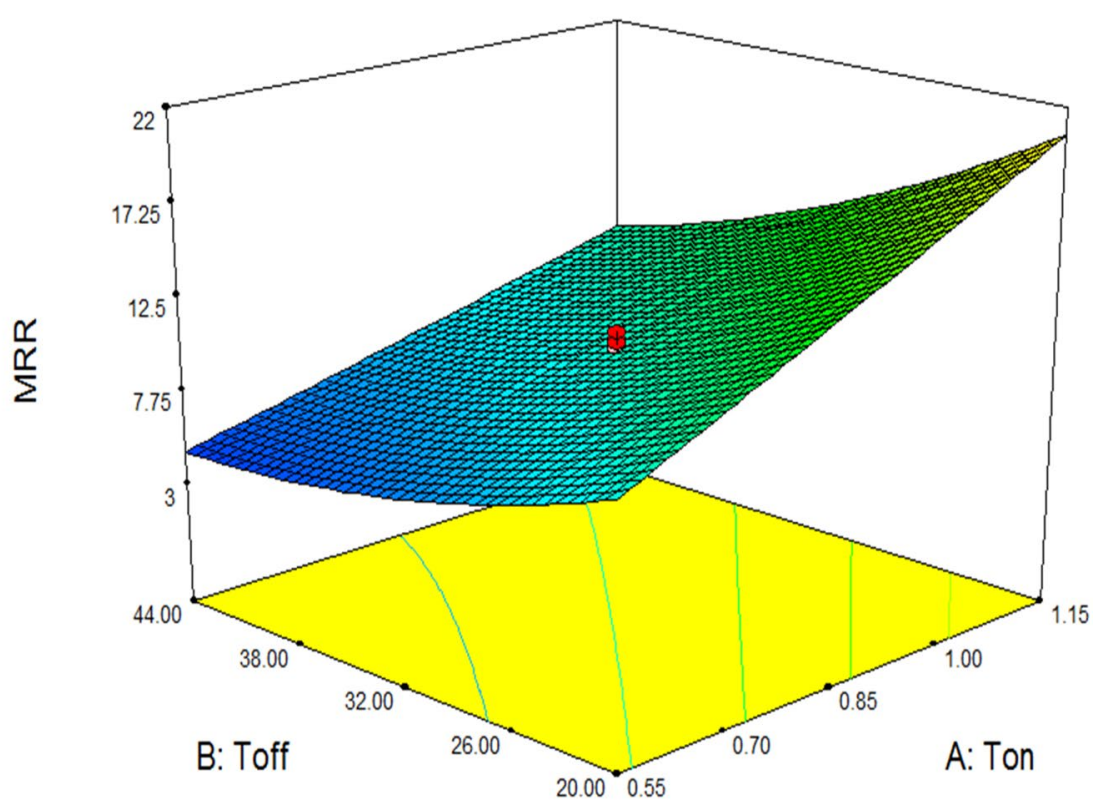

Fig. 10 Interaction plot ( $T_{\text {on }}$ vs. $\left.T_{\text {off }}\right)$ for MRR

Design-Expert@ Software

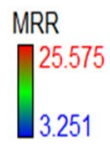

$\mathrm{X} 1=\mathrm{A}:$ Ton

$\mathrm{X} 2=\mathrm{C}: \mathbb{P}$

Actual Factor

B: Toff $=32.00$

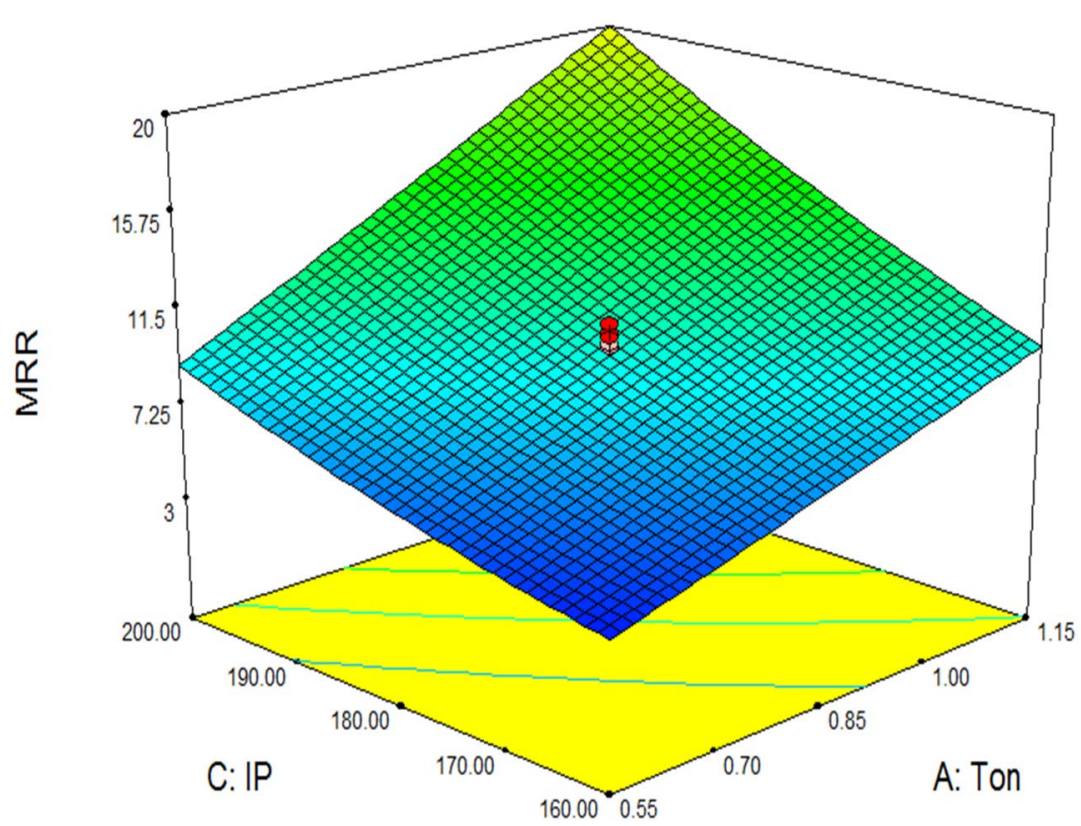

Fig. 11 Interaction plot ( $T_{\text {on }}$ vs. IP) for MRR

presence of reinforced particles has decreased the density but raises the melting point of the composite and consequently, leading to deterioration of MRR, when compared to the conventionally stirred with gravity cast MMCs and stir cum squeeze casted high-strength aluminium alloy $[13,33,34]$. High discharge energy is required to melt the

\section{SN Applied Sciences}




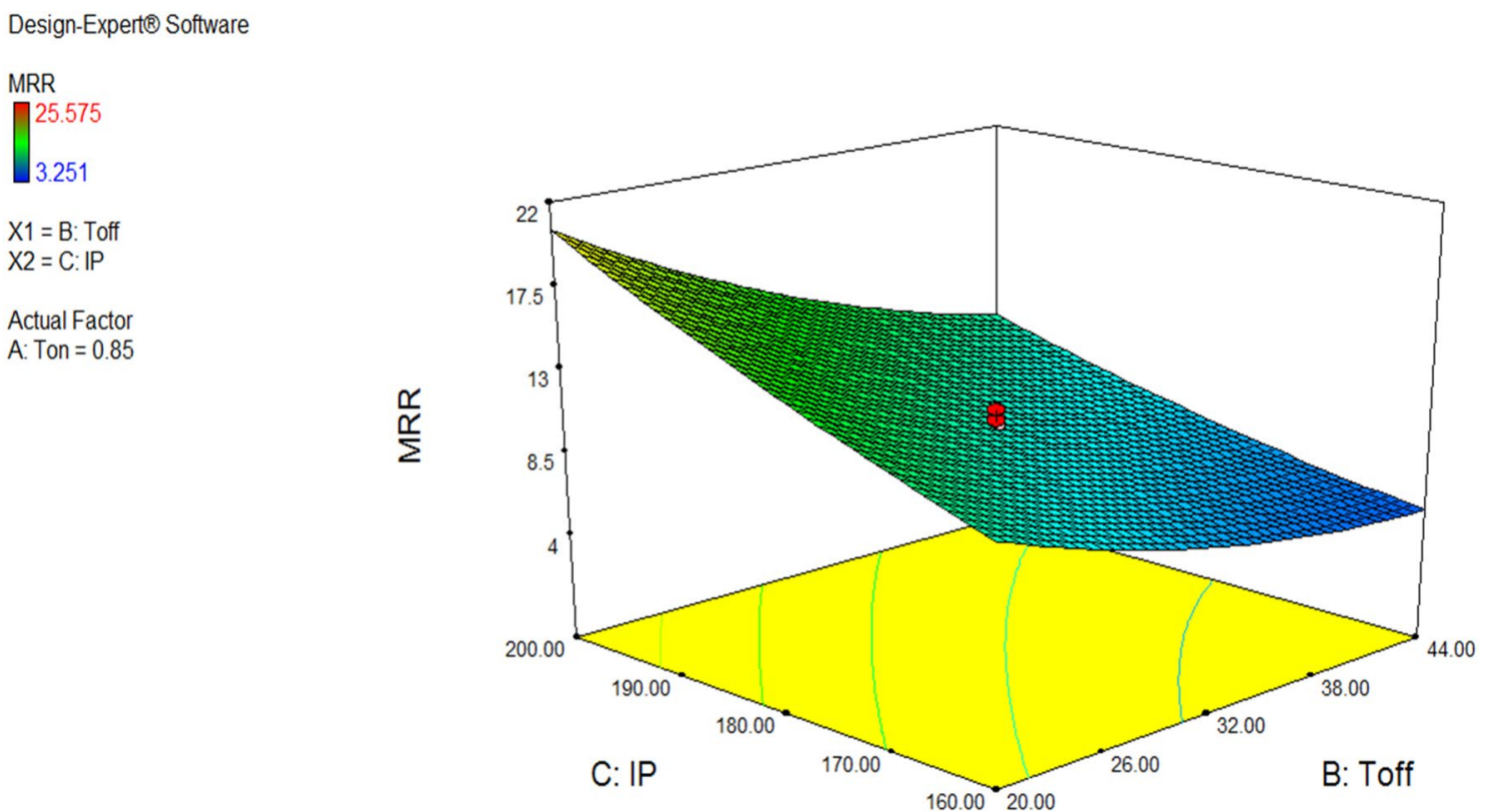

Fig. 12 Interaction plot ( $T_{\text {off }}$ Vs. IP) for MRR

A413 with 12 wt $\% \mathrm{~B}_{4} \mathrm{C}$ composites as a result of strong bonding created by the applied pressure in the stir cum squeeze casting process. Also, it was observed that the shallow craters, recast layer, the absence of crack and particle pull out are considered as inaccuracy for machined samples in normal conventional stirred with gravity cast specimen. But, it was eliminated from the machined surfaces in the present work because of high-strength stir cum squeeze cast pore-free tightly bonded uniform distributed composites [35]. Therefore, to obtain effective machining with higher MRR without affecting the work material quality, there must be a proper balance between the IP and maximum $T_{\text {on }}$.

In WEDM process, $T_{\text {off }}$ was a pause for the sparking to remove the debris accumulated during $T_{\text {on }}$ (sparking). By increasing $T_{\text {off }}$ value, the discharges occur in smaller numbers for a specified time period and it propagates to a lesser discharge of energy which causes sluggish and less amount of material removal. Decreasing the pulse off time lesser than the minimum level produces an insufficient removal of the debris. Therefore a minimum pulse off time must be maintained to obtain higher MRR [14, 35].

\subsubsection{Surface roughness analysis on machining composites}

The F-value (29.93) of the ANOVA model indicated that the predicted model is highly significant one. It was also clear that only a possibility of $0.01 \%$ for "Model $F$-Value" to occur owing to noise. The other variables in the model were produced with values less than 0.0500 for " $P>F$ " which means these terms were highly important. In this experimental study $A, B, C, A B, A C, C 2$ were the noteworthy model items that are used to represent the input variables and their respective interactions. The parameters whose values are more than 0.0500 were denoted as non-significant terms. Thus $A, B$ and $C$ were the most significant factors, the non-significant terms were $A^{2}$, $B C$, and $B^{2}$. The lack of fit obtained was not due to the pure error when the "lack-of-fit $F$-value" is 3.30. The noise produces a "lack-of-fit $F$-value" with $10.78 \%$ accidental chance. The "predicted R-squared" of 0.7494 exhibits a sensible agreement with "adjacent R-squared" (0.9320). The ratio between signal and noise is shown in "adequate precision." For the better signal, the required ratio was greater than 4, now this value of 22.569 shows an adequate signal. The normal plots of residual were presented in Fig. 13. The errors were distributed normally as the residuals in the plot were placed along the linear straight line. Therefore, the model developed was in equal fit with the measured values. The residual vs. predicted fits were presented in Fig. 14 and these plots specified that the residuals were structure-less. Equation 4 shows the second-order equation developed for SR considering all the above-mentioned points is presented. 
Design-Expent Software

$S R$

Color points by value of

SR:

618

4.14

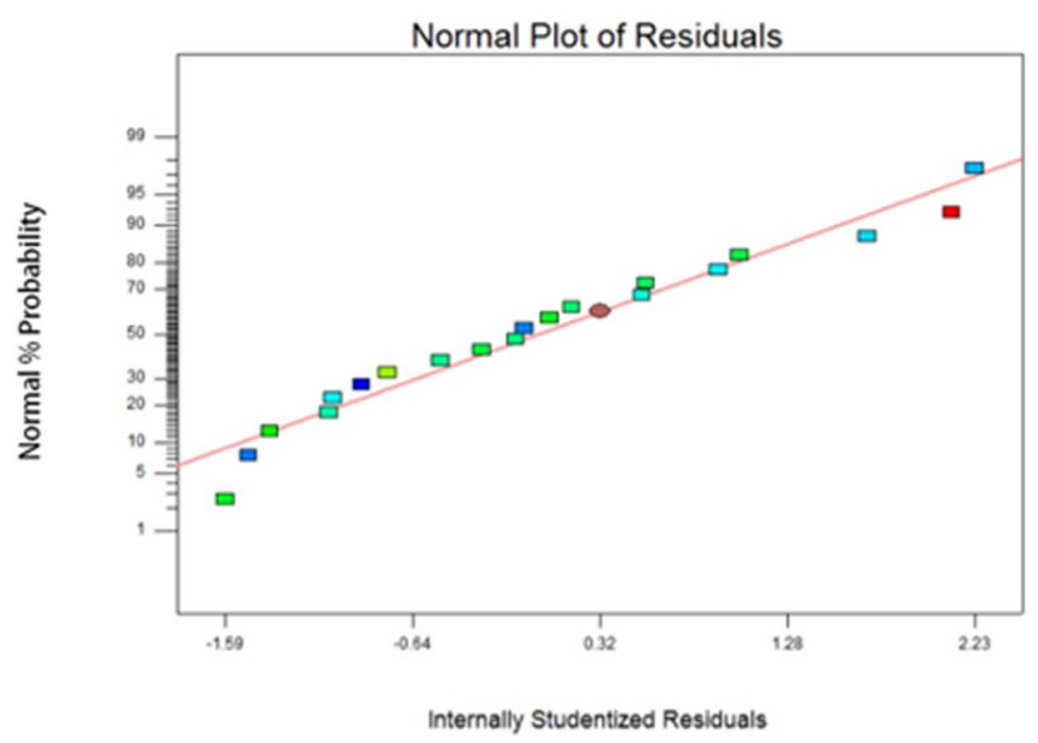

Fig. 13 Normal plot of residuals for SR

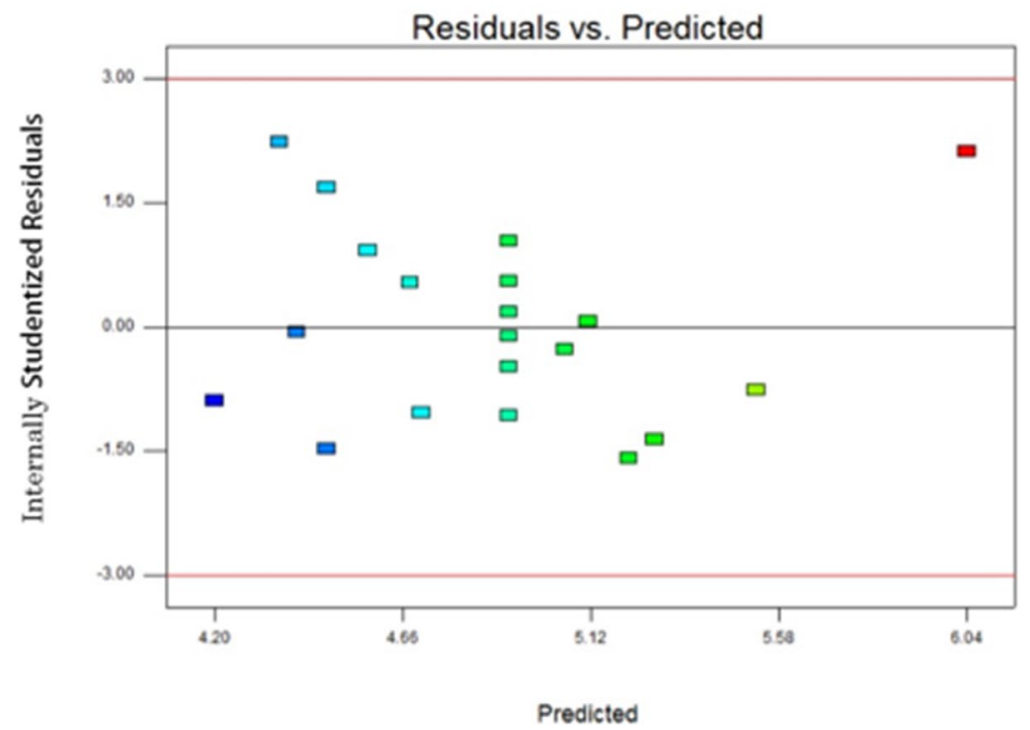

Fig. 14 Residual versus predicted plot for SR

$$
\begin{aligned}
\mathrm{SR}= & -3.94433-2.39708 * T_{\text {on }}+0.063005 * T_{\text {off }} \\
& +0.082475 * \mathrm{Ip}-0.048264 * T_{\text {on }} * T_{\text {off }}+0.026458 * T_{\text {on }} * \mathrm{Ip} \\
& -2.55208 E-004 * T_{\text {off }} * \mathrm{Ip}+0.17027 * T_{\text {on }}^{2}+1.43248 E \\
& -004 * T_{\text {off }}^{2}-2.31273 E-004 * \mathrm{Ip}^{2}
\end{aligned}
$$

By using ANOVA, all the input process parameters were considered and it was identified that the $T_{\text {on }}$ was the important factor that has the highest impact in the output SR with a contribution of $41.08 \%$. IP and $T_{\text {off }}$ have the second and third impact with $27.02 \%$ and $11.62 \%$, respectively, as shown in Table 6 . From the collective 
Table 6 ANOVA for SR

\begin{tabular}{llrlrlll}
\hline Source & Sum of squares & DF & Mean of square & $F$ value & Contribution\% & $P$ value & Significant \\
\hline Model & 3.56 & 9 & 0.40 & 29.93 & 96.21 & $<0.0001$ & $*$ \\
A-T $_{\text {on }}$ & 1.52 & 1 & 1.52 & 114.55 & 41.08 & $<0.0001$ & $*$ \\
B-T $_{\text {off }}$ & 0.43 & 1 & 0.43 & 32.51 & 11.62 & 0.0002 & \\
C-IP & 1.00 & 1 & 1.00 & 75.69 & 27.02 & $<0.0001$ & $*$ \\
AB & 0.24 & 1 & 0.24 & 18.25 & 6.48 & 0.0016 & \\
AC & 0.20 & 1 & 0.20 & 15.24 & 5.40 & 0.0029 & \\
C & 0.12 & 1 & 0.12 & 9.32 & 3.24 & 0.0122 & \\
Residual & 0.13 & 10 & 0.013 & & 3.51 & & \\
Lack of fit & 0.10 & 5 & 0.020 & 3.30 & 2.70 & & 0.1078 \\
Pure error & 0.031 & 5 & $6.147 \mathrm{E}-003$ & & 0.83 & & \\
Total & 3.70 & 19 & & & & & \\
\hline R & & & & & &
\end{tabular}

R-squared: 0.9642, adj R-squared: 0.9320, pred R-squared: 0.7494, adeq precision: 22.569

*Significant
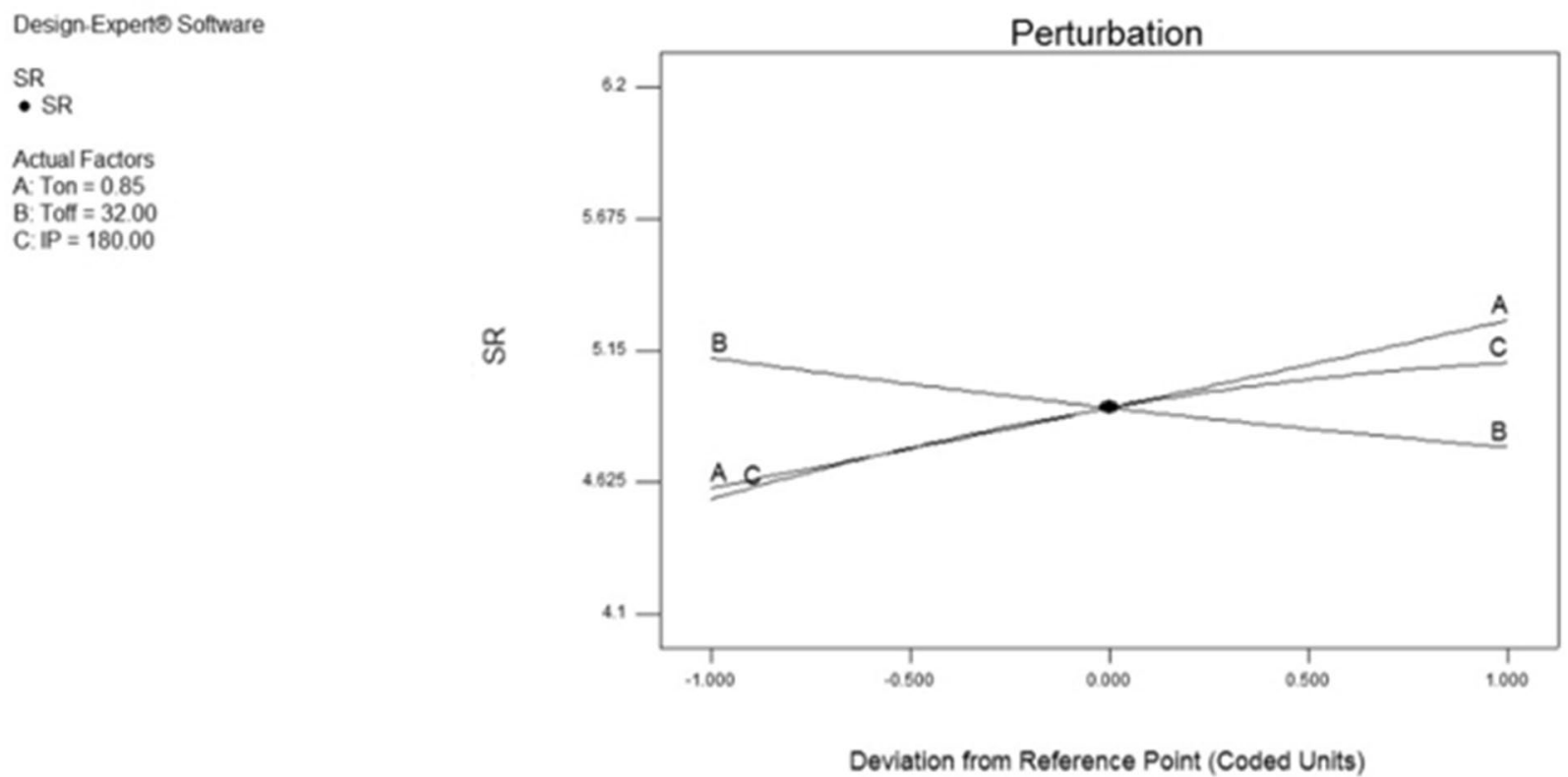

Fig. 15 Perturbation plot for SR

perturbation response graph; Fig. 15, it was observed experimentally that when $\mathrm{T}_{\text {on }}$ and IP rises, an increase in $S R$ is obtained whereas $S R$ steeps down as $T_{\text {off }}$ improves. Figure 16 indicates that the improvement of SR with the rise in $T_{\text {on }}$ and fall in $T_{\text {off }}$. Figure 17 hints that there was an abundant increase in SR when both $\mathrm{T}_{\text {on }}$ and IP increases. Figure 18 discloses that SR value is enhanced by disproving $T_{\text {off }}$ value and improving the IP.

The longer spark duration produced due to a rise in $T_{\text {on }}$ and IP results in high-intensity current transferred from wire to work piece resulted in a formation of shallow craters. The depth of the shallow craters during machining of composites and recast layer might not be the major cause for increasing SR. The particle size and height of protruding $\mathrm{B}_{4} \mathrm{C}$ particles in the matrix in the machined surface, corresponding shallow crater depth and recast layer show the overall roughness of the surface. However, the increase in $T_{\text {on }}$ and IP for machining the sample leads to a higher range of SR. Also, it was observed that the absence of particle pullout from the machined surface because of stir cum squeeze cast leading to a pore-free tightly bonded uniform distributed composite with a nominal $12 \mathrm{wt} \% \mathrm{~B}_{4} \mathrm{C}$ particles. As expected, the stir cum squeeze cast specimen showed lower SR value to the conventionally stirred with gravity casted MMCs work material [30,33]. The electrode and 
Design-Expert® Software

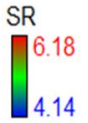

$\mathrm{X} 1=\mathrm{A}:$ Ton

$\mathrm{X} 2=\mathrm{B}:$ Toff

Actual Factor

$C: \mathbb{P}=180.00$

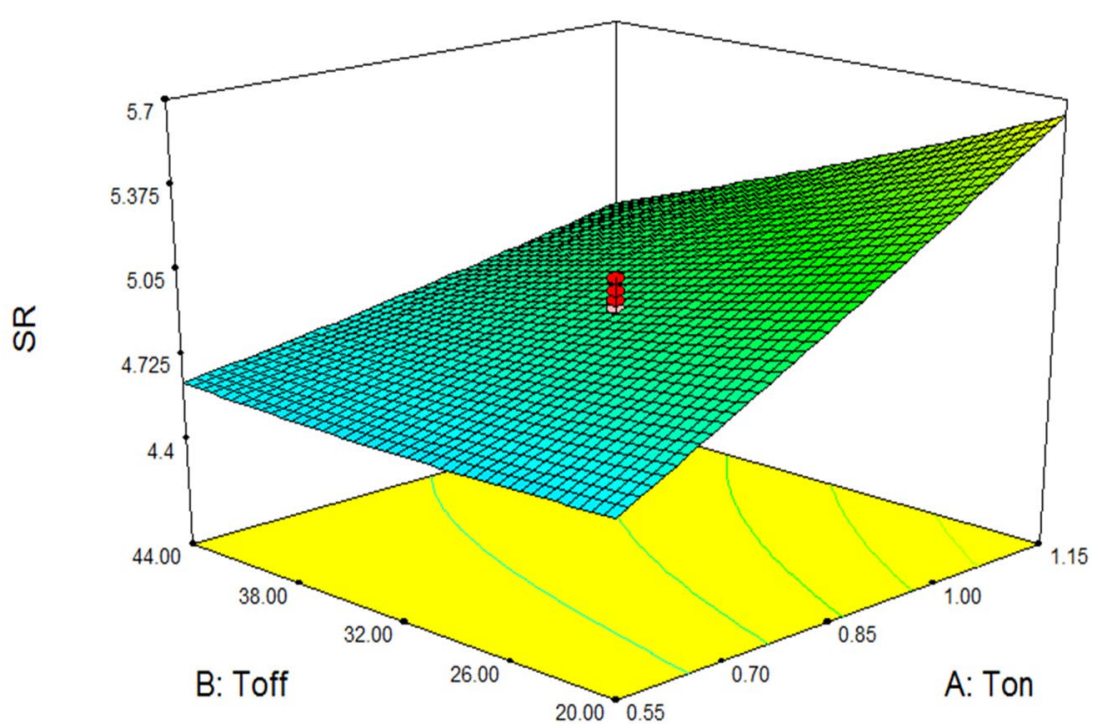

Fig. 16 Interaction plot ( $T_{\text {on }}$ vs. $\left.T_{\text {off }}\right)$ for $S R$

Design-Expert@ Software

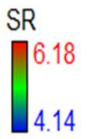

$\mathrm{X} 1=\mathrm{A}:$ Ton

$\mathrm{X} 2=\mathrm{C}: \mathrm{IP}$

Actual Factor

B: Toff $=32.00$

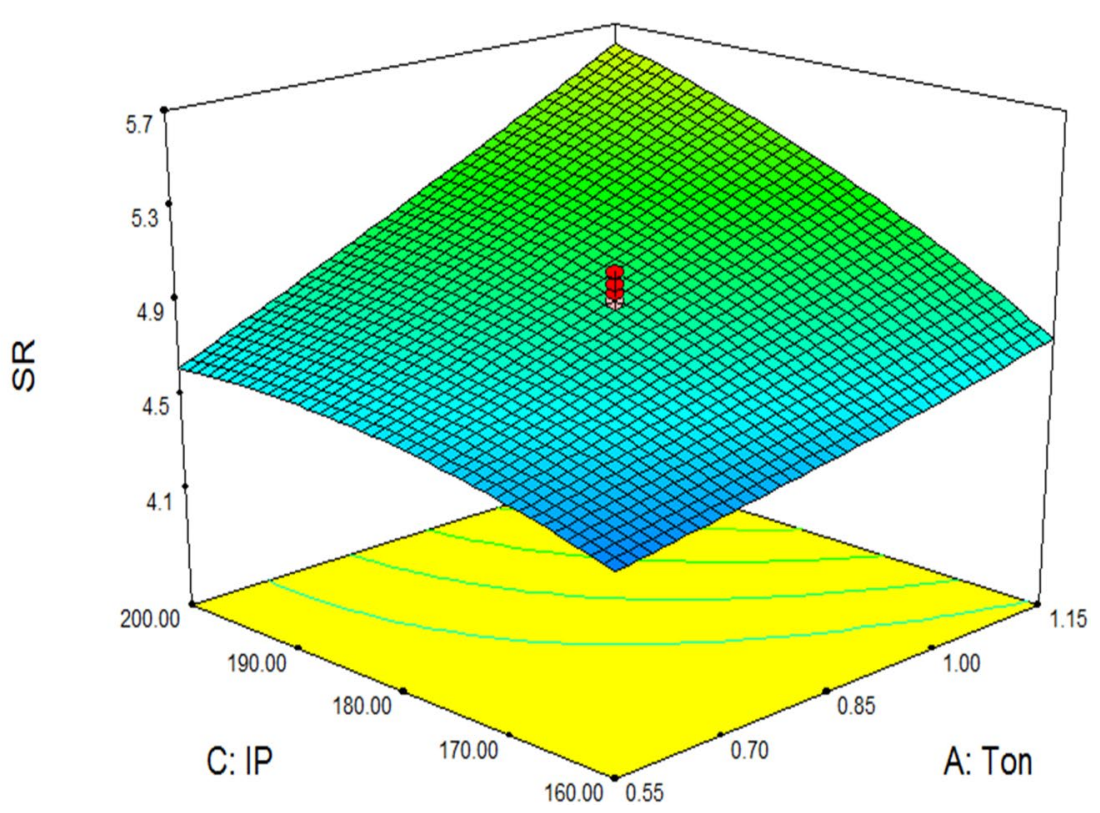

Fig. 17 Interaction plot ( $T_{\text {on }}$ Vs. IP) for SR

material have generated bombarding forces in-between because of high discharge energy transferred by $T_{\text {on }}$ and IP affects the surface properties of the machined components [36]. It was found that there was a decrease in $S R$ with increase in $T_{\text {off }}$ because of the smaller amount of energy discharge striking the surface of composite for a specified time period which ensured in a few numbers of shallow craters and progressively removed tightly bonded $\mathrm{B}_{4} \mathrm{C}$ particles without pull out from the matrix on the stir cum squeeze cast work piece surface. Thus, 
Design-Expert® Software

SR

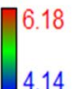

$\mathrm{X} 1=\mathrm{B}:$ Toff

$\mathrm{X} 2=\mathrm{C}: \mathrm{IP}$

Actual Factor

A: Ton $=0.85$

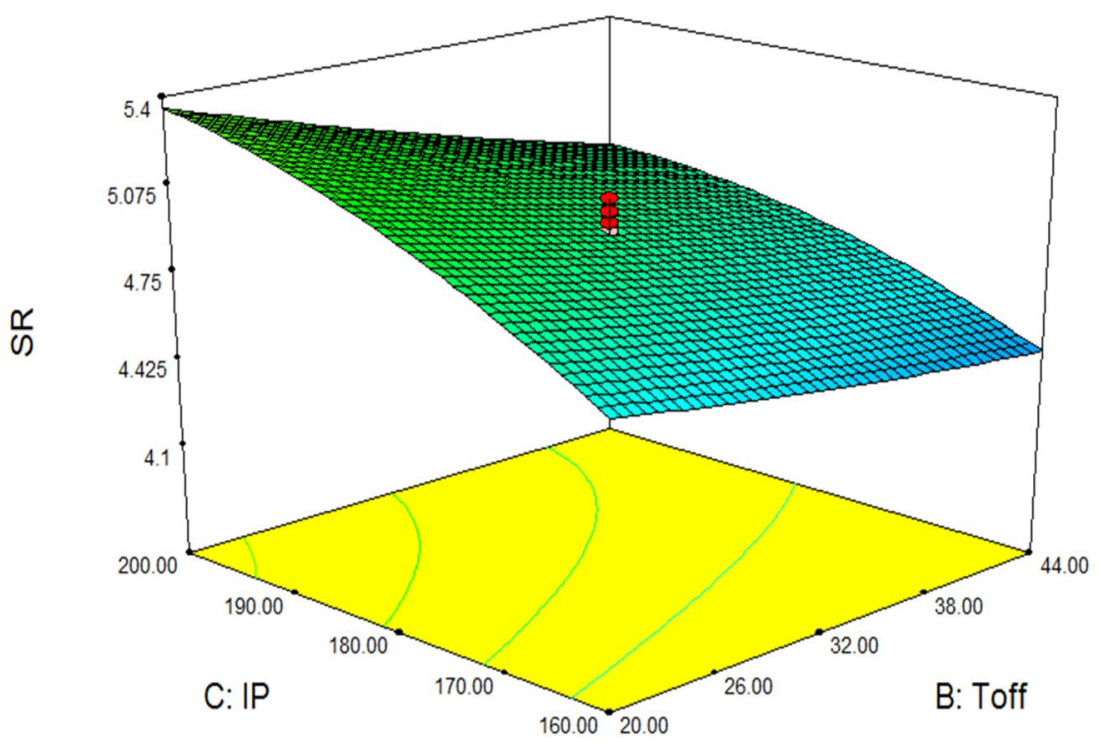

Fig. 18 Interaction plot ( $T_{\text {off }}$ Vs. IP) for SR

the uneven disparity in the surface roughness was minor due to high-strength stir cum squeeze cast specimen [36-38].

\subsection{Additivity test for experimental versus predicted sets}

The validation of the responses shown in Eqs. 3 and 4 is done by performing an additivity test for MRR and SR. Figures 19 and 20 show the graphical relationship and deviation between the RSM predictions and the end responses of the experimental data for SR and MRR of the composites. It can be noted from the graphs that there was no appreciable deviation and hence the overall error of the mathematical data to the real-time data was $6.47 \%$ and $1.52 \%$ for MRR and SR, respectively, which is low and hence the mathematical model is reliable. The conclusion from this test is that the developed RSM model would predict almost accurately the MRR and SR values and hence it can be used for the prediction of these values for different set-ups for monetary and temporal benefits.

\subsection{Multi-objective optimization using desirability approach}

The objective function, $D(X)$ was used in this technique, which is known as a desirability function. It portrays the enviable ranges for apiece response (di). Appropriate ranges were between zero (least desirable) and one

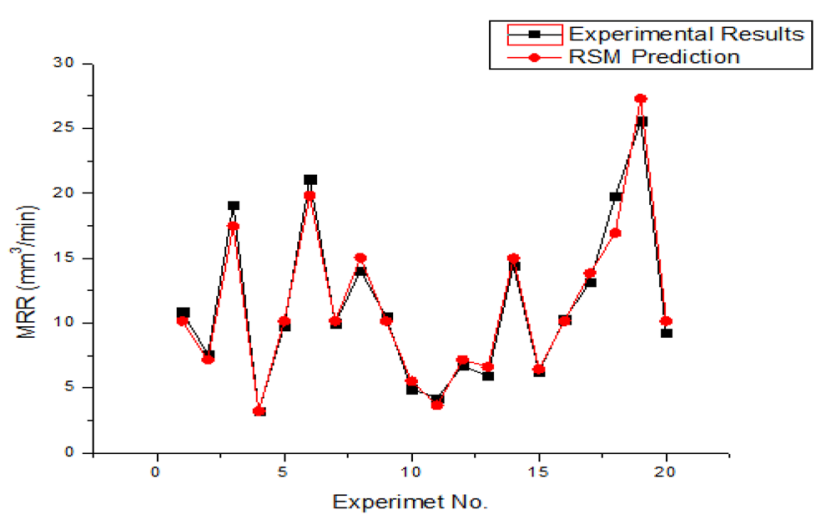

Fig. 19 Experiment sets versus RSM predication for MRR

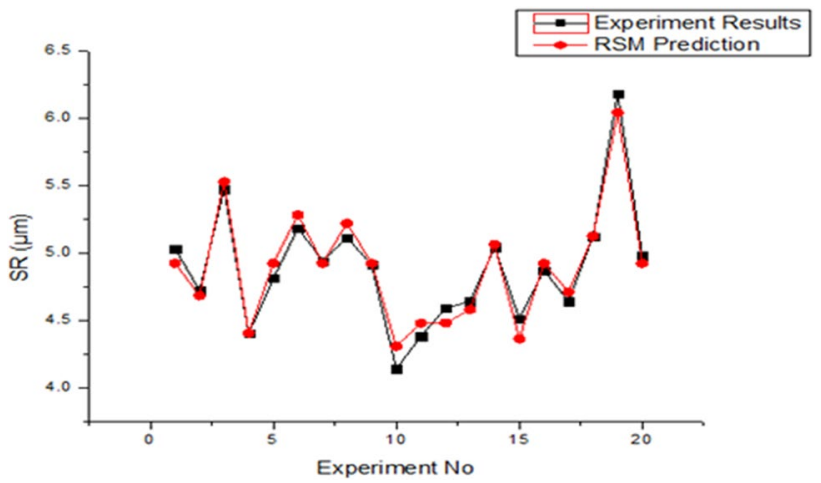

Fig. 20 Experiment sets versus RSM predication for SR 
(most desirable). The instantaneous response is given by the simultaneous objective function and is revealed by Eq. 5.

$D=\left(d^{1} \times d^{2} \times \ldots d^{n}\right)^{1 / n}$

In Eq. (5), ' $n$ ' denotes the measured quantity of output values. Here the output obtained was 0 when if any one of the responses generated was beyond the desirable range. Each goal was allotted by a response with a high and low value for simultaneous optimization. On the worksheet, for "Goal" arena there should be one the five options for the responses: "none", "maximum", "minimum", "target", or "in range". The performance response would not be considered for optimization when the goal is none. For any number of responses, components and factors goals could be set but at a minimum one response must be involved in the target set. In the desirability objective function $D(X)$, an importance relative for the additional responses can be assigned for each solution. The importance of $r_{i}$ varies from the minimum important $(+)$ a value of 1 , to the maximum important $(+++++)$ a value of 5 . There was a decrease in simultaneous objective and settles to normal form for desirability when all the important values were the same.

In this experimentation, the desirability function method was taken for obtaining multi-response optimization of WEDM process parameters on stir cum squeeze cast $\mathrm{A} 413$ with $12 \mathrm{wt} \% \mathrm{~B}_{4} \mathrm{C}$ composites machining. Various criteria, for instance, the weights and importance, were varied for three combinations of measuring trials. The higher MRR condition, importance value of $5(+++++)$ are agreed for MRR and a lower importance value of $1(+)$ was agreed for SR. In the next condition the equal MRR and $S R$, an importance value of $3(+++)$ was agreed equally for MRR and SR. In final the best
SR condition, importance value of 1(+) was agreed for MRR and the best importance value of $5(+++++)$ was agreed for SR. The ideal results are tabulated in Table 7.

\subsection{Validation tests}

The multi-response optimization through the processing of WEDM parameters for stir cum squeeze cast A413 with $12 \mathrm{wt} \% \mathrm{~B}_{4} \mathrm{C}$ composites was verified using validation test runs for re-confirming. The percentage of error among optimal experimental trail values for the response is shown in Table 8.

The scientific community has investigated and reported WEDM process parameters for machining various commercially available materials. After a scientific study of this exclusive stir cum squeeze cast composite material, the factors that contribute to its properties have been mathematically studied and graphically exhibited and the WEDM process parameters for best possible results have been suggested.

\subsection{Quality characteristics}

The quality characteristics of composites machined surface would influence the amount of ceramic particles of $12 \mathrm{wt} \% \mathrm{~B}_{4} \mathrm{C}$ having particle size of $44 \mu \mathrm{m}$. The effective bonding of the reinforced ceramic particles within the matrix, the grain structure of composites, and the equal distribution of reinforced ceramic particles in the matrix determines the quality of the machined surface. Figure $21 \mathrm{a}$ shows a machined higher MRR sample surface quality, it shows electrode wire impression due to higher $T_{\text {on }}$. In which $T_{\text {on }}$ of $1.04 \mu \mathrm{s}, T_{\text {off }} 21 \mu \mathrm{s}$, IP 200 Amp on around MRR $24.455 \mathrm{~mm}^{3} / \mathrm{mm}$, SR $5.753 \mu$ s was obtained. Followed by
Table 7 Multi-response optimization of WEDM process parameter

Table 8 Results of validation test

\begin{tabular}{|c|c|c|c|c|c|c|}
\hline \multirow[t]{2}{*}{ Performance measures } & \multicolumn{3}{|c|}{ Input factor } & \multicolumn{2}{|l|}{ Output response } & \multirow[t]{2}{*}{ Desirability } \\
\hline & $T_{\text {on }}(\mu \mathrm{s})$ & $T_{\text {off }}(\mu \mathrm{s})$ & IP (Amp) & $\operatorname{MRR}\left(\mathrm{mm}^{3} / \mathrm{min}\right)$ & $\mathrm{SR}(\mu \mathrm{m})$ & \\
\hline Higher MRR & 1.04 & 21.00 & 200 & 24.455 & 5.753 & 0.738 \\
\hline Equal MRR \& SR & 0.65 & 20.00 & 200 & 16.103 & 4.926 & 0.595 \\
\hline Best RA & 0.55 & 20.03 & 200 & 13.842 & 4.708 & 0.673 \\
\hline
\end{tabular}

\begin{tabular}{|c|c|c|c|c|c|c|c|c|c|}
\hline \multirow[t]{2}{*}{ S. No } & \multicolumn{3}{|c|}{ Input factor } & \multicolumn{2}{|c|}{$\begin{array}{l}\text { Output response experi- } \\
\text { mental }\end{array}$} & \multicolumn{2}{|c|}{$\begin{array}{l}\text { Output response pre- } \\
\text { dicted }\end{array}$} & \multicolumn{2}{|c|}{$\%$ Error } \\
\hline & $T_{\text {on }}(\mu \mathrm{s})$ & $T_{\text {off }}(\mu \mathrm{s})$ & $\overline{I P(A m p)}$ & $\operatorname{MRR}\left(\mathrm{mm}^{3} / \mathrm{min}\right)$ & $\mathrm{SR}(\mu \mathrm{m})$ & $\mathrm{MRR}\left(\mathrm{mm}^{3} / \mathrm{min}\right)$ & $\mathrm{SR}(\mu \mathrm{m})$ & MRR & SR \\
\hline 1 & 1.04 & 21.00 & 200 & 24.455 & 5.753 & 24.332 & 5.741 & 0.5 & 0.20 \\
\hline 2 & 0.65 & 20.00 & 200 & 16.103 & 4.926 & 16.056 & 4.922 & 0.3 & 0.08 \\
\hline 3 & 0.55 & 20.03 & 200 & 13.842 & 4.708 & 13.856 & 4.709 & 0.1 & 0.02 \\
\hline
\end{tabular}



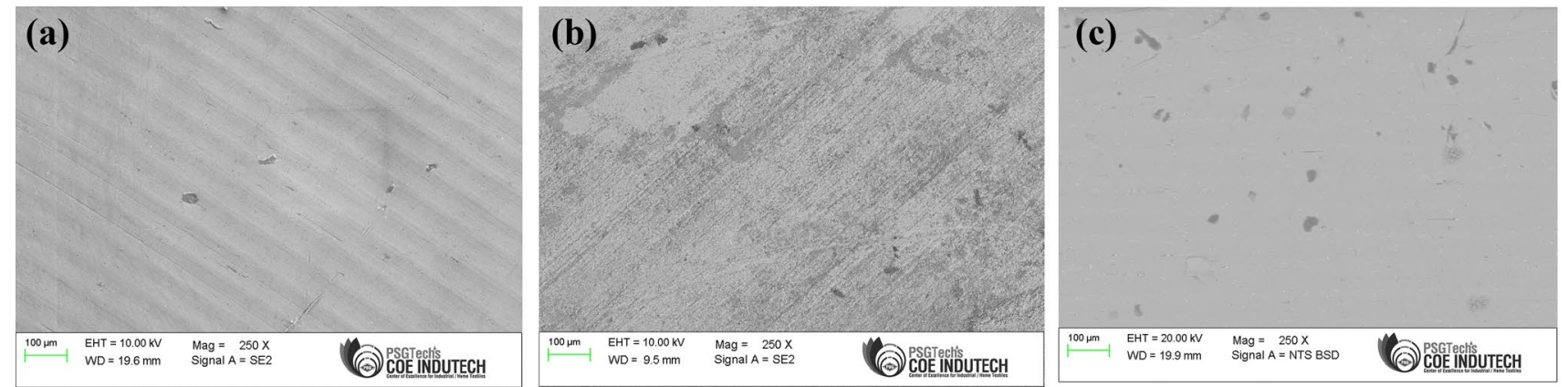

Fig. 21 a SEM image of machined higher MRR sample surface, $\mathbf{b}$ SEM image of machined equal MRR and SR sample surface, $\mathbf{c}$ SEM image of machined fine SR sample surface

Fig. $21 \mathrm{~b}$ shows a machined equal MRR and SR surface quality with nominal effect of the machine sample. In which $T_{\text {on }}$ of $0.65 \mu \mathrm{s}, T_{\text {off }} 20 \mu \mathrm{s}$, IP 200 Amp on around MRR 16.103 $\mathrm{mm}^{3} / \mathrm{mm}$, SR $4.926 \mu$ s was obtained. Also Fig. 21c shows a machined fine SR surface quality with best effect of the machine sample. In which $T_{\text {on }}$ of $0.55 \mu \mathrm{s}, T_{\text {off }} 20.03 \mu \mathrm{s}$, IP $200 \mathrm{Amp}$ on around MRR $13.842 \mathrm{~mm}^{3} / \mathrm{mm}$, SR $13.842 \mu \mathrm{s}$ was obtained. The machined stir cum squeeze casted composites has no negative effect was being observed in the machined surface's, which shows great potential for improving machined surface quality. So it's evident that the quality and integrity of the machined surface improved because of good bonding with densification, fine structure, elimination of particle pullout/plucking and absence of surface micro-cracks due to stir cum squeezing casting processing route.

\section{Conclusions}

In the present investigation, the development of A413 with $12 \mathrm{wt} \% \mathrm{~B}_{4} \mathrm{C}$ composites through stir cum squeeze casting technique is being performed and taken for WEDM process to study the response systematically. The key findings being drawn are as follows:

- The fabricated composites exhibited a higher hardness of $136 \mathrm{VHN}$, and $373 \mathrm{MPa}$ ultimate tensile strength was obtained significantly with the addition of $\mathrm{B}_{4} \mathrm{C}$ particles of harder and stiffer material in the soft $A 413$ alloy. Also coupled with processing of stir cum squeeze casting technique confirmed through SEM observations, the sound quality pore-free uniform dispersion of the matrix and the reinforcements result in superior bonding.

- In short, $\mathrm{B}_{4} \mathrm{C}$ particles resist plastic deformation and applied squeeze pressure increases the densification, thereby increasing grain boundary of particles within the matrix resulting in strengthening of the composites.

- The major goal of this work is to facilitate effective parameter selection while machining of developed composites by WEDM process through systematic design approach by RSM technique. The influenced process parameters $T_{\text {on }}, T_{\text {off }}$ IP on MRR and SR are optimized.

- The statistical analysis based on ANOVA prediction is the most significant one for dominating control parameters like $T_{\text {on }}$ and IP than least influenced parameter of $T_{\text {off }}$ on more MRR and $T_{\text {off }}$ significantly directs the better SR in WEDM process based on their contribution.

- The performance of the additivity test showed that the RSM results and experimental results were in pace with each other for average error percentage of around $6.47 \%$ and $1.52 \%$ for MRR and SR correspondingly.

- The desirability approach for using multi-objective optimization to seek the best parametric combinations of higher MRR, equal significance for both MRR and SR and the best SR was obtained with good concurrence through confirmation test in which the outcome of this research would offer a successful protocol of machined surface quality characteristics, and it was evident from SEM images which majorly contributes processing of composites through stir cum squeezing casting technique.

Data availability The experimental datasets obtained from this research work and then the analysed results during the current study are available from the corresponding author on reasonable request.

\section{Compliance with ethical standards}

Conflict of interest The authors declare that they have no conflict of interest. 


\section{References}

1. Veeresh Kumar GB (2011) Chinta swamy prakash Rao and Selvaraj N, Mechanical and Tribological Behavior of Particulate Reinforced Aluminum Metal Matrix Composites - a review. Journal of Minerals and Materials Characterization and Engineering 10(01):59-91. https://doi.org/10.4236/jmmce.2011.101005

2. Nturanabo F, Masu L, Kirabira JB (2019) Novel applications of aluminium metal matrix composites. Alum Alloys Compos. https ://doi.org/10.5772/intechopen.86225

3. Asiflqbal AKM, Nuruzzaman DM (2016) Effect of the reinforcement on the mechanical properties of aluminium matrix composite: a review. Int J Appl Eng Res 11(21):10408-10413

4. Shorowordi KM, Tahar Laoui ASM, Haseeb A, Celis JP, Froyen $L$ (2003) Microstructure and interface characteristics of B4C, $\mathrm{SiC}$ and $\mathrm{Al} 2 \mathrm{O} 3$ reinforced $\mathrm{Al}$ matrix composites: a comparative study. J Mater Process Technol 142(3):738-743. https://doi. org/10.1016/S0924-0136(03)00815-X

5. Kennedy AR, Karantzalis AE (1999) The incorporation of ceramic particles in molten aluminium and the relationship to contact angle data. Mater Sci Eng A 264(1-2):122-129. https://doi. org/10.1016/S0921-5093(98)01102-2

6. Balasivanandha Prabu S, Karunamoorthy L, Kathiresan S, Mohan B (2006) Influence of stirring speed and stirring time on distribution of particles in cast metal matrix composite. J Mater Process Technol 171(2):268-273. https://doi.org/10.1016/j.jmatprotec .2005.06.071

7. Ghomashchi MR, Vikhrov A (2000) Squeeze casting: an overview. J Mater Process Technol 101(1-3):1-9. https://doi.org/10.1016/ S0924-0136(99)00291-5

8. Dhanashekar M, Senthil Kumar VS (2014) Squeeze casting of aluminium metal matrix composites: an overview. Procedia Eng 97:412-420. https://doi.org/10.1016/j.proeng.2014.12.265

9. Mazahery A, OstadShabani M (2014) Mechanical properties of squeeze-cast $\mathrm{A} 356$ composites reinforced with $\mathrm{B}_{4} \mathrm{C}$ particulates. J Mater Eng Perform 21:247-252. https://doi.org/10.1007/s1166 5-011-9867-6

10. Ghoreishi R, Roohi AH, Dehghan Ghadikolaei A (2018) Analysis of the influence of cutting parameters on surface roughness and cutting forces in high speed face milling of $\mathrm{Al} / \mathrm{SiC}$ MMC. Mater Res Exp. https://doi.org/10.1088/2053-1591/aad164

11. Yanming $Q, Z$ Zhou Z (2000) Tool wear and its mechanism for cutting $\mathrm{SiC}$ reinforced aluminium matrix composites. J Mater Process Technol 100(1-3):194-199. https://doi.org/10.1016/S0924 -0136(99)00405-7

12. Klocke F, Zeis M, Klink A, Veselovac D (2013) Technological and economical comparison of roughing strategies via milling, sinking-EDM, wire-EDM and ECM for titanium- and nickelbased blisks. CIRP J Manuf Sci Technol 6(3):198-203. https://doi. org/10.1016/j.cirpj.2013.02.008

13. Sathishkumar D, Kanthababu M, Anburaj R, Thirumalai Sundarrajan $\mathrm{N}$, Arul $\mathrm{H}$ (2011) Investigation of wire electrical discharge machining characteristics of Al6063/SiCp composites. Int J Adv Manuf Technol 56:975-986. https://doi.org/10.1007/s0017 0-011-3242-5

14. Pramanik A (2014) Developments in the non-traditional machining of particle reinforced metal matrix composites. Int J Mach Tools Manuf 86:44-61. https://doi.org/10.1016/j.ijmachtool s.2014.07.003

15. Sivaprakasam P, Hariharan P, Gowri S (2015) Optimization of micro-WEDM process of aluminium matrix composite (A413-B4C), a response surface approach. Mater Manuf Process 28(12):1340-1347. https://doi.org/10.1080/10426 914.2013.823502

SN Applied Sciences

APRINGER NATURE journa
16. Suresh Kumar S, Uthayakumar M, Thirumalai Kumaran $S$, Parameswaran P, Mohandas E (2014) Electrical discharge machining of $\mathrm{Al}$ (6351)-5\% SiC-10\% $\mathrm{B}_{4} \mathrm{C}$ hybrid composite: a grey relational approach. Model Simul Eng. https://doi. org/10.1155/2014/426718

17. Mahanta $S$, Chandrasekaran M, Samanta S, Arunachalam RM (2018) EDM investigation of Al 7075 alloy reinforced with B4C and fly ash nanoparticles and parametric optimization for sustainable product. J Braz Soc Mech Sci Eng 40:263. https://doi. org/10.1007/s40430-018-1191-8

18. Srivastava AK, Nag A, Dixit AR, Hloch S, Tiwari S, Scucka J, Pachauri $P$ (2018) Surface integrity in wire-EDM tangential turning of in situ hybrid metal matrix composite $A 359 / B_{4} C / A_{2} O_{3}$. Sci Eng Compos Mater. https://doi.org/10.1515/secm-2017-0391

19. Muralidharan N, Chockalingam K, Parameshwaran R, Kalaiselvan K, Nithyavathy N (2020) Optimization of CNC-WEDM parameters for AA2024/ZrB2 in situ stir cast composites using response surface methodology with desirability function technique. Arab J Sci Eng. https://doi.org/10.1007/s13369-020-04490-x

20. Kumar H, Manna A, Kumar R (2018) Modeling of process parameters for surface roughness and analysis of machined surface in WEDM of Al/SiC-MMC. Trans Indian Inst Met 71:231-244. https ://doi.org/10.1007/s12666-017-1159-X

21. Zhang Y, Zhang Z, Zhang G, Li W (2020) Reduction of energy consumption and thermal deformation in WEDM by magnetic field assisted technology. Int J Precis Eng Manuf Green Technol 7:391-404. https://doi.org/10.1007/s40684-019-00086-5

22. Lal S, Kumar S, Khan ZA, Siddiquee AN (2014) Multi-Response optimization of wire electrical discharge machining process parameters for $\mathrm{Al} 7075 / \mathrm{SiC} / \mathrm{Al}_{2} \mathrm{O}_{3}$ hybrid composite using taguchi-based grey relational analysis. J Eng Manuf 229:229-237. https://doi.org/10.1177/0954405414526382

23. Myers RH, Montgomery DC, Anderson-Cook CM (2002) Response surface methodology: process and product optimisation using designed experiments. Wiley, New York

24. Shadab M, Singh R, Rai RN (2018) Multi-objective optimization of wire electrical discharge machining process parameters for Al5083/7\%B4C composite using metaheuristic techniques. Arab J Sci Eng. https://doi.org/10.1007/s13369-018-3491-9

25. Gurusamy N, Natarajan J, Palaniappan PK (2019) Parameter optimization of the CNC wire-cut EDM process for machining aluminium 6063-B ${ }_{4} \mathrm{C}$ metal matrix composites. JTrans FAMENA 43:91-108. https://doi.org/10.21278/TOF.43408

26. Erdemir F (2017) Study on particle size and X-ray peak area ratios in high energy ball milling and optimization of the milling parameters using response surface method. Meas J Int Meas Confed 112:53-60. https://doi.org/10.1016/j.measuremen t.2017.08.021

27. Vijayabhaskar S, Rajmohan T (2019) Experimental investigation and optimization of machining parameters in WEDM of nano$\mathrm{SiC}$ particles reinforced magnesium matrix composites. J Silicon 11:1701-1716. https://doi.org/10.1007/s12633-017-9676-0

28. Shandilya P, Jain PK, Jain NK (2013) RSM and ANN modeling approaches for predicting average cutting speed during WEDM of $\mathrm{SiC}_{\mathrm{p}} / 6061 \mathrm{Al}$ MMC. Procedia Eng 64:767-774. https://doi. org/10.1016/j.proeng.2013.09.152

29. Suresh Kumar S, Erdemir F, Varol T, Thirumalai Kumaran S, Uthayakumar M, Canakci A (2020) Investigation of WEDM process parameters of $\mathrm{Al}-\mathrm{SiC}-\mathrm{B}_{4} \mathrm{C}$ composites using response surface methodology. Int J Lightweight Mater Manuf 3(2):127-135. https://doi.org/10.1016/j.ijlmm.2019.09.003

30. Soundararajan R, Ramesh A, Mohanraj N, Parthasarathi N (2016) An investigation of metal removal rate and surface roughness of squeeze casted A413 alloy on WEDM by multi response optimization using RSM. Int J Alloys Compd 685:533-545. https:// doi.org/10.1016/j.jallcom.2016.05.292 
31. Chaudhari R, Vora J, Parikh DM, Wankhede V, Khanna S (2020) Multi-response optimization of WEDM parameters using an integrated approach of RSM-GRA analysis for pure titanium. J Inst Eng India Ser D. https://doi.org/10.1007/s40033-020-00204-7

32. Das A, Sarkar S, Karanjai M, Sutradhar G (2017) Application of box-behnken design and response surface methodology for surface roughness prediction model of CP-Ti powder metallurgy components through WEDM. J Inst Eng India Ser D. https://doi. org/10.1007/s40033-017-0145-0

33. Soundararajan R, Ramesh A, Sivasankaran S, Vignesh M (2017) Modelling and analysis of mechanical properties of aluminium alloy (A413) reinforced with boron carbide $\left(B_{4} C\right)$ processed through squeeze casting process using artificial neural network model and statistical technique. Mater Today Proc 4:2008-2030

34. Ekici E (2015) Ali RizaMotorcu and AbdilKus, Evaluation of surface roughness and material removal rate in the wire electrical discharge machining of $\mathrm{Al} / \mathrm{B}_{4} \mathrm{C}$ composites via Taguchi method. J Compos Mater 23:1-12. https://doi.org/10.1177/0021998315 609788
35. El-Gallab M, Sklad M (1998) Machining of Al/SiC particulate metal matrix composites: Part II workpiece surface integrity. J Mater Process Technol 83(1-3):277-285. https://doi. org/10.1016/S0924-0136(98)00072-7

36. Rao TB, Krishna GA (2014) Selection of optimal process parameters in WEDM while machining Al7075/SiCp metal matrix composites. Int J Adv Manuf Technol 73(1-4):299-314. https://doi. org/10.1007/s00170-014-5780-0

37. Kumar SS, Uthayakumar M, Kumaran ST, Parameswaran P (2014) Electrical discharge machining of $\mathrm{Al} 6351-\mathrm{SiC}-\mathrm{B}_{4} \mathrm{C}$ hybrid composite. Mater Manuf Process 29(11-12):1395-1400. https://doi. org/10.1080/10426914.2014.952024

38. Garg SK, Manna A, Jain A (2014) An investigation on machinability of $\mathrm{Al} / 10 \% \mathrm{ZrO} 2(\mathrm{P})$ metal matrix composite by WEDM and parametric optimization using desirability function approach. Arab J Sci Eng 39(4):3251-3270. https://doi.org/10.1007/s1336 9-013-0941-2

Publisher's Note Springer Nature remains neutral with regard to jurisdictional claims in published maps and institutional affiliations. 